\title{
Antidiabetic and anti-obesity acylated flavonol diglucoside from Ammannia baccifera L. subsp. aegyptiaca (Willd.) Koehne Waste
}

Noha Swilam ( $\square$ noha.swilam@bue.edu.eg )

British University in Egypt

Mahmoud Nawwar

National Research Centre

Rasha Radwan

Sinai University

Eman Mostafa

Modern Sciences and Arts University

\section{Research Article}

Keywords: Ammania aegyptiaca, Myricetin 3-0- $\beta-4 C \neg 1-(6$ "-0-galloylglucopyranoside) 7-0- $\beta-4 C \neg 1$ glucopyranoside, Digestive enzymes, Molecular docking, Obesity, Type 2 diabetes, Streptozotocin

Posted Date: December 10th, 2020

DOl: https://doi.org/10.21203/rs.3.rs-116589/v1

License: (9) This work is licensed under a Creative Commons Attribution 4.0 International License. Read Full License 


\section{Abstract}

Chemical investigation of the aerial parts of Ammania aegyptiaca ethanol extract (AEEE) revealed significant high concentrations of polyphenols and flavonoids content with notable antioxidant activity in DPPH, ORAC, and reducing power assay. New acylated diglucoside flavonol myricetin 3-0- $\beta-4 C 1-(6 "-0-$ galloyl glucopyranoside) 7-0- $\beta$-4C1-glucopyranoside (MGGG) was isolated from aerial parts of AEEE along with four additional known phenolics, not characterized previously from AEEE. Moreover, powerful inhibitory effects of MGGG, AEEE, and all isolates against a-amylase, pancreatic lipase and $\beta$ glucosidase, were assessed. In addition, flexible molecular docking was used to reveal the inhibition towards digestive enzymes and confirmed that the MGGG interacted strongly with the active site residues of these enzymes with the highest binding free energy against $\beta$-glucosidase ( $D G=-8.98 \mathrm{kcal} / \mathrm{mol}$ ) compared to the commercial drug Acarbose, thus justifying its dual management of diabetes and obesity. In streptozotocin (STZ) induced diabetic rats, AEEE significantly decreased high serum glucose, aamylase activity, liver and kidney function markers and increased insulin level. Moreover, it improved lipid profile due to diabetes with increased SOD activity and inhibited of TBARS formation. Consequently, AEEE and MGGG are found useful in controlling the secondary complications associated with type 2 diabetes mellitus. Histopathological studies proved the decrease in the pancreas damage and agreed with the biochemical findings. These results provide evidence that AEEE and MGGG have potent antidiabetic activity, which warrants additional investigations.

\section{Introduction}

Diabetes Mellitus (DM) is a major metabolic disorder leading to high morbidity and mortality rate all over the world [1]. The incidence of diabetes in developing countries have reached to epidemic proportions and International Diabetes Federation (IDF) expects an increase from 382 million people with diabetes to 592 million between 2013 and 2035 [2].

It is characterized by elevated plasma glucose concentrations caused by either insufficient insulin or insulin resistance, or both. In addition to, abnormalities in different metabolic pathways [3]. As the disease progresses, it results in complications like retinopathy, neuropathy, nephropathy, stroke, ischemic heart disease, peripheral vascular disease and a variety of heterogeneous diseases [4]. More than $95 \%$ of which are type 2 diabetes (T2D). It develops as a result of insulin resistance and pancreatic $\beta$-cell dysfunction, resulting in hyperglycemia [5] .

Interestingly, it was found that there is a direct link between T2D and obesity. Obesity leads to increased cytokines production, fat disposition in body tissues and mitochondrial dysfunction which results in insulin resistance and pancreatic $\beta$-cell apoptosis [6].

The current treatment for T2D is the usage of oral hypoglycemic. On the other hand, insulin replacement therapy is the main treatment for patients with type 1 diabetes [7]. However, major undesirable effects of 
such drugs are the main cause for an urgent need for alternative therapies that may have no side-effects [8].

As a consequence there is a growing interest in phytomedicine for using plant extracts which are more safe, easily available, more affordable and have less incidence of adverse effects in comparison to synthetic antihyperglycemic drugs[9].

A beneficial approach for management of diabetes is to reduce the post-prandial hyperglycemia and to prevent lipids digestion and absorption. This is unswervingly associated with the preclusion of obesity and obesity-related diseases [10].

Exploring natural inhibitors of hydrolyzing enzymes in carbohydrates and lipids digestion can offer an attractive combinatorial therapeutic strategy for the management/prevention of postprandial hyperglycemia and obesity.

Moreover, DM appears to be an oxidative stress-related endocrine disorder and using antioxidants may be beneficial in its prophylaxis and treatment [11]. Aforementioned studies reported that in T2D the oxidative stress is increased due to chronic hyperglycemia leading to manufacture of reactive oxygen species (ROS) in $\beta$-cells, thereby depletes the antioxidant mechanism activity with enhancement of free radical generation [12]. Consequently, medicinal plants rich in antioxidant phytoconstituents can shield $\beta$-cells from reactive oxygen species (ROS) and can avoid diabetes induced by ROS [13].

Increasing evidence suggests that plant phenolic offer potential therapeutic antioxidant activities which are related to their capacity to scavenging a wide range of ROS [14].

So, looking for a relevant source of plant phenolics as potential therapeutic agents which can be used for decreasing blood glucose levels and lipids for dual control of diabetes and obesity via digestive enzyme inhibition, specifically pancreatic a-amylase, intestinal $\beta$-glucosidase and pancreatic lipase [15], along with its ability to boost the body antioxidant system become an absolute necessity.

One of the famous plants genera which include phenolic-rich species is the genus Ammannia (Lythraceae). This genus is known to embrace species capable of synthesizing and accumulating high percent of phenolics [16]. Ammannia baccifera L. subsp. aegyptiaca (Willd.) Koehne Waste (AE) is an annual herb distributed in tropical regions, in Egypt, it was recorded in Nile and Oasis geographical regions. It grows as a summer weed in rice fields, ditches and swamps [17]. It is often treated as a synonym, variety of subspecies of Ammannia baccifera L., eg. [18]. However, AE is an accepted species separated from the other three species known from Egypt by its sessile or subsessile flowers in compact axillary cymes. The type of this species was collected from Damietta, Egypt [17]. In folk medicine, its fruit has been mixed with ginger and this juice was useful in fever treatment [19]. Providing the available current literature is concerned, the phenolic profile and biological activities of AE have never been investigated. However, other species has been reported to have antidiabetic activity [20]. 
This study aimed to subject the flowering whole plant ethanol extract (AEEE) of $A E$ to an intensive phytochemical investigation of its phenolic constituents and to investigate the in vitro antioxidant activity of AEEE and the isolated constituents. Along with evaluation of their inhibitory effects and antidiabetic activity against the extra pancreatic digestive enzymes and to use molecular docking analysis to demarcate their inhibition toward digestive enzymes. Furthermore, evaluation of the possible antidiabetic activity of the flowering whole plant ethanol extract AEEE in streptozotocin (STZ) induced diabetic rats in order to assess the dual antidiabetic and anti-obesity effects of AEEE. This provide a related data for further study and its utilization as an adjuvant therapy in the management of T2D diabetes and obesity. Being a weed, which mainly threatens water channels and rice fields, this study has focused on the exploitation and utilization of this plants in the pharmaceutical field.

\section{Results}

\section{Total phenolic and flavonoid contents}

Phenolic content of AEEE was determined as $380.5 \pm 3.88 \mathrm{mg} \mathrm{GAE} / \mathrm{g}$, where $\mathrm{R}^{2}=0.9985$, and the equation for standard curve is $Y=0.0242 X+0.0211$. In addition, the total flavonoid content in the AEEE was evaluated as $190 \pm 2.31 \mathrm{mg} \mathrm{CE} / \mathrm{g}$, where $\mathrm{R}^{2}=0.9989$, and the equation for standard curve is $\mathrm{y}=0.0048 \mathrm{x}+$ 0.0091 . So AEEE was found to be a source of wide range of potent polyphenolic constituents.

\section{Identification of polyphenols from AEEE}

Concentrated aqueous ethanol extract (3:1) AEEE was prepared from a fresh aerial part samples of AE. AEEE was fractionated over column chromatography over Sephadex LH 20, using water/methanol mixtures of decreasing polarities, followed by column fractionation over $\mathrm{MCl}$ gel of the 30 and $50 \%$ aqueous methanol Sephadex LH 20 column fractions afforded pure samples of compounds (1-5). The known compounds (2-5) showed chromatographic, UV absorption and hydrolytic data identical with those reported for kaempfeol 3-O-rutinoside 2 [21], quercetin 3-O-rutinoside 3 [22], tellimagranidine-I 4 [16] and 2,3-a, $\beta$-digalloy glucose 5 [23], respectively. Compound 1, a yellow amorphous powder, showed chromatographic properties (dark purple spot on paper chromatogram under UV light, turning reddish orange when fumed with ammonia vapor, moderate migration in aqueous and organic solvents). UV spectral analysis of 1 in methanol and on addition of shift reagents $[24,25]$ confirmed the presence of a flavonol moiety with a free hydroxyl at 4'-position (stable MeONa spectrum in UV) and a substituted hydroxyl at the 7-position (showed no shift in UV with $\mathrm{NaOAc}$ ). Acid hydrolysis of $\mathbf{1}$ yielded glucose (cochromatography), myricetin and gallic acid (co-chromatography and ${ }^{1} \mathrm{H}$ NMR). Enzymatic hydrolysis with $\beta$-glucosidase yielded intermediate $1 \mathrm{a}$, with molecular ion $[\mathrm{M}-\mathrm{H}]^{-}$at $\mathrm{m} / \mathrm{z}=631$ in $\mathrm{ESI} / \mathrm{MS}$ corresponding to a molecular weight of $632 .{ }^{1} \mathrm{H}-\mathrm{NMR}$ spectrum DMSO $d_{6}$ ) of 1 a displayed two resonances at $\mathrm{dppm} 4.17$ (m) and $4.28(\mathrm{~d}, \mathrm{~J}=12 \mathrm{~Hz})$, assignable to two non-equivalent methylene glucose protons. The anomeric proton was found resonating at $\mathrm{d} \mathrm{ppm} 5.28$ as a doublet $(\mathrm{J}=8 \mathrm{~Hz}$ ), thus proving a $b$-configuration of the sugar moiety. In this spectrum, the galloyl moiety exhibited the resonance of its two equivalent $\mathrm{H}-2$ "' and $\mathrm{H}-6^{\text {"'I }}$ protons as a singlet at $\mathrm{d}$ ppm 6.98. The chemical shifts of the remaining glucose protons were 
found resonating in the region between $\delta \mathrm{ppm} 3.95$ and 3.3, hidden by $\mathrm{H}_{2} \mathrm{O}$ proton signals, while the myricetin proton resonances were located at $\delta 7.48\left(\mathrm{~s}, \mathrm{H}-2{ }^{\prime}, \mathrm{H}-6^{\prime}\right), 6.16(\mathrm{IH}, \mathrm{d}, \mathrm{J}=2 \mathrm{~Hz}, \mathrm{H}-6), 6.39(\mathrm{IH}, \mathrm{d}, \mathrm{J}=2$ $\mathrm{Hz}, \mathrm{H}-8)$, thus confirming the structure of intermediate $1 \mathrm{a}$ as myricetin $3-O-b$-(6"-O-galloylglucoside). Consequently, 1 is myricetin 3-O- $\beta$-(galloyl glucoside)-7-O-glucoside. Negative ESI/MS 1 consistent with this view and showed a molecular ion peak at $[\mathrm{M}-\mathrm{H}]^{-}: 793.27$, consistent to molecular mass 794 . Structure 1 and the site of attachment of the galloyl moiety to the 3-O-glucoside moiety was confirmed by NMR analysis. The ${ }^{1} \mathrm{H}$ NMR spectrum of $1\left(\right.$ DMSO- $\left._{6}\right)$ showed two anomeric hexose proton signals at $\delta$ ppm 5.33 and 5.02 (with $\mathrm{d}, \mathrm{J}=8.5 \mathrm{~Hz}$ ) corresponding to the anomeric glucoside moieties at the 3- and 7positions, respectively. In addition to a pair of methylene glucose proton signals at $\delta 4.26(d, J=12 \mathrm{~Hz})$ and $4.12(\mathrm{~m})$, attributed to the two glucose protons at the C-6" carbon with hydroxyl group is acylated by the galloyl moiety. Signals of the two methylene protons in the 7-O-glucoside moiety and the rest of glucose protons overlapped with water protons signal showed upfield signals in the region from $\delta 3.3$ to 3.9. Characteristic protons of the galloyl moiety displayed signal at $\delta 7.02$. In addition, 7-O-substituted myricetin moiety was evidenced by proton signals at $\delta 6.3(\mathrm{~d}, \mathrm{~J}=2.5 \mathrm{~Hz})$ and $6.75(\mathrm{~d}, \mathrm{~J}=2.5 \mathrm{~Hz}$ ), attributed to the $\mathrm{H}-6$ and $\mathrm{H}-8$ of this moiety [26]. The ${ }^{13} \mathrm{C}$ NMR analysis established the structure of 1 . It exhibited twelve glucose carbon signals. The two $\beta$-glucose anomers were detected at $\delta$ ppm 99.2 and 99.8 , while the methylene $\mathrm{C}-6$ "' glucose carbon with a free hydroxyl and methylene glucose $\mathrm{C}-6$ " resonate upfield at $\delta$ ppm 60.2 and 63.2 respectively. Acylation by gallic acid resulted in de-shielding of the second resonance. The remaining glucose carbons were found resonating at $\delta \mathrm{ppm}$ closely related to those reported to flavonols 3,7- di-O-glycoside [27]. The presence of only one galloyl moiety in 1 followed from the single carboxyl carbon resonance at $\delta 166.5$ and from the recognized characteristic pattern of the remaining galloyl carbons. Substitution at the 3- and 7-positions of myricetin was tracked from the relative up-field shifts of C-3 and C-7 signals to $\delta 134.4$ and 161.6, respectively. Downfield shifts of the signals corresponding $o$-and $p$-carbons in comparison with the corresponding signals of myricetin was detected [27]. Furthermore, ${ }^{4} C_{1}$ conformer of the two glucose moieties was confirmed from the measured chemical shift values of the carbon resonances. Consequently, 1 is identified as, myricetin $3-O-\beta^{4} C_{1}^{-}$- 6 "- $O$-galloyl glucopyranosid)-7-O- $\beta^{4} C_{1}$-glucopyranoside, which has not been reported previously in nature Fig. 1.

(Fig.1): Myricetin3-O- $\beta^{4} C_{7}$-(6"-O-galloylglucopyranoside)-7-O- $\beta^{4} C_{1-\text { glucopyranoside }}$

\section{Molecular docking}

The molecular docking analysis was performed by using MOE 2015 Software to predict the possible binding mechanism of MGGG with three targeted enzymes. In this study, interactions between the docking sites of enzymes and the phenolic molecule and some relevant parameters were applied for molecular docking analysis.

All of the molecular docking results regarding interactions between the molecule of MGGG, reference standards and digestive enzymes binding are summarized in (Table $\mathbf{1}$ ) and Fig. $\mathbf{2}$. In order to prove the reliability of the docking process, the native ligand derived from the X-ray crystallographic structures was redocked into the active sites of $a$-amylase as shown in Fig. 2 (A1),The binding mode of MGGG exhibited 
an energy binding of $-8.80 \mathrm{kcal} / \mathrm{mol}$ and the complex was stabilized by four hydrogen bonds, one polar hydrogen bond with carbonyl group in chromone nucleus formed (green dash lines) with His 305 residue of the binding pocket of $a$-amylase with a distance of $2.55 \AA$, while hydroxyl groups in B-ring and galloylted glucose moieties formed another three acidic and basic hydrogen bonds with Asp300, Glu233 and Lys200 with distance of $2.11,2.41$ and $2.15 \AA$ respectively. The binding mode of the commercial drug Acarbose which used as a positive control exhibited an energy binding of $-7.23 \mathrm{kcal} / \mathrm{mol}$ and formed three hydrogen bonds, one acidic hydrogen bond with hydroxyl group in 4,6-dideoxyo-a-D-glucopyranosyl moiety (green dash lines) with Asp 300 residue of the binding pocket of the a-amylase with distance of $2.17 \AA$, while hydroxyl groups in $a$-D-glucopyranose moiety formed another two basic hydrogen bonds with Lys200 with distance of 2.16, $2.23 \AA$ Aig. 2 (A2).

\section{Modeling of MGGG binding mode against $\alpha$-amylase}

The X-ray crystal structure and enzyme kinetics studies have revealed that the active site of $a$-amylase is characterized by the presence of three important residues namely Asp197, Glu233, and Asp300 [28]. It was reported that among the amino acid residues of a-amylase interacting with myricetin (an inhibitor of a-amylase) were Trp59, Lys200, Leu162, Val163, Ala198, and Glu233 [28]. A previous study found that aamylase inhibitors such as curcumin, interacted with the amino acid residues Lys200, Glu233, and Asp300, while rutin and quercetin interacted with the amino acid residues Try59, His305, Thr163, and Lys200 [29]. Therefore, the docking results confirmed MGGG had similarities with acarbose as they interacted with several key amino acids residues Asp300 and Lys200 of $a$-amylase, suggesting that those two amino acid residues may play an important role in the inhibitory activities of the two compounds.

\section{Modeling of MGGG binding mode on $\beta$-glucosidase}

$\beta$-glucosidase active site of MGGG is characterized by the presence Trp425, Asn426 and Phosphate ion. A previous study found that quercetin fixed in the binding pocket of $\beta$-glucosidase mainly through hydrogen bonds and hydrophobic interactions between the complexes. The residues involved in $\mathrm{H}$-bonds were mainly polar amino acids, such as Trp442, Gln57 and Asn426 [30]. The molecular docking illustrated that MGGG bind strongly to $\beta$-glucosidase catalytic site with an energy binding of $-8.98 \mathrm{kcal} / \mathrm{mol}$. Hydroxyl groups in $\beta$-D-glucopyranose moiety formed one polar hydrogen bond with $\mathrm{G} \ln 165$ (green dash lines) of the active pocket of $\beta$-glucosidase with a distance of 2.00, $2.40 \AA$ and two strong metal ion interactions with $\mathrm{PO}_{4}$ group attached (black dash lines) with Trp425 and Asn426 residues Fig. 2 (B1). In addition, MGGG and Acarbose Fig. 2 (B2) can form metal ion interactions with $\beta$-glucosidases via some common residues, namely Trp425 and Asn426. It can be speculated that these amino acids are extraordinarily critical to the binding of the two ligands with glucosidase enzyme, suggesting that MGGG is a good hypoglycemic agent. The magnitude of the binding energy indicates that MGGG showed the strongest interaction with $\beta$-glucosidase, confirming the in vitro data.

Modeling of MGGG binding mode on pancreatic lipase 
MGGG was able to bind to the active site of pancreatic lipase. The values of the binding free energy was$7.01 \mathrm{kcal} / \mathrm{mol}$. $\beta$-D-glucopyranose moiety formed one polar hydrogen bond with Asn385 with a distance of $2.19 \AA$, while galloylglucose moiety formed another acidic hydrogen bond with Thr355 with a distance of $2.02 \AA$ Fig. 2 (C1). Moreover, the binding mode of the reference Orlistat exhibited an energy binding of $-5.62 \mathrm{kcal} / \mathrm{mol}$ with a carbonyl group in formamide moiety formed one polar hydrogen bond with Tyr389 with a distance of $2.31 \AA$. While other carbonyl group formed another basic hydrogen bond with Lys387 with distance of $2.30 \AA \AA$ and hydrophobic aliphatic tail show H-arene interaction with Phe410 Fig. 2 (C2). it was reported that rutin and isorhamnetin-3-O-rutinoside interacted with the amino acid residues Asn 320 and Asn 176 of pancreatic lipase, respectively [31]. For all tested digestive enzymes, mapping surface technique was carried out to show MGGG occupying the active pocket of these enzymes Fig. 3.

Table (1): Analysis results of the molecular dockings into $\alpha$-amylase, $\beta$-glucosidase and pancreatic lipase ligands.

\begin{tabular}{|c|c|c|c|c|c|c|c|}
\hline \multirow[t]{2}{*}{ Enzyme } & \multirow[t]{2}{*}{ Compound } & \multicolumn{3}{|c|}{ Bonds NO. } & \multirow{2}{*}{$\begin{array}{l}\text { Score } \\
\text { (DG) } \\
\mathrm{kcal} / \mathrm{mol}\end{array}$} & \multirow{2}{*}{$\begin{array}{l}\text { RMSD } \\
\text { value }\end{array}$} & \multirow[t]{2}{*}{ E-place } \\
\hline & & H.B & $\mathrm{Pi}$ & Metal ion interaction & & & \\
\hline \multirow[t]{2}{*}{ a-Amylase } & MGGG & 4 & 0 & - & -8.80 & 2.11 & -122.43 \\
\hline & Acarbose & 3 & 0 & - & -7.23 & 2.59 & -89.60 \\
\hline \multirow[t]{2}{*}{$\beta$-Glucosidase } & MGGG & 1 & 0 & 2 & -8.98 & 1.64 & -148.63 \\
\hline & Acarbose & 1 & 1 & 3 & -7.87 & 2.17 & -103.97 \\
\hline \multirow[t]{2}{*}{ Pancreatic lipase } & MGGG & 2 & 0 & - & -7.01 & 1.66 & -138.43 \\
\hline & Orlistate & 2 & 1 & - & -5.62 & 2.66 & -62.27 \\
\hline
\end{tabular}

\section{In-vitro studies}

\section{DPPH assay}

The antioxidant activity of AEEE, MGGG, and the isolated compounds (2-5) were evaluated using the DPPH assay. The $\mathrm{IC}_{50}$ values were $6.12 \pm 0.83 \mu \mathrm{g} / \mathrm{mL}, 2.37 \pm 0.56 \mu \mathrm{g} / \mathrm{mL},>100 \pm 13.67 \mu \mathrm{g} / \mathrm{mL}, 8.81 \pm 1.05$ $\mu \mathrm{g} / \mathrm{mL}, 4.64 \pm 0.39 \mu \mathrm{g} / \mathrm{mL}$ and $4.81 \pm 0.73 \mu \mathrm{g} / \mathrm{mL}$, respectively compared to that of Vit. C (the positive control) with an $\mathrm{IC}_{50}$ of $1.83 \pm 1.41 \mu \mathrm{g} / \mathrm{mL}$, reflecting a potent antioxidant activity of MGGG.

\section{ORAC assay}

The antioxidant activity of AEEE, MGGG, and the separated compounds (2-5) evaluated using the more specialized ORAC assay. The $\mathrm{IC}_{50}$ values were $5.92 \pm 1.03 \mu \mathrm{g} / \mathrm{mL}, 2.01 \pm 0.23 \mu \mathrm{g} / \mathrm{mL}$, > $100 \pm 10.17 \mu \mathrm{g} / \mathrm{mL}, 8.02 \pm 0.85 \mu \mathrm{g} / \mathrm{mL}, 4.14 \pm 1.27 \mu \mathrm{g} / \mathrm{mL}$ and $4.43 \pm 0.68 \mu \mathrm{g} / \mathrm{mL}$ respectively. All values were 
lower than Trolox (the positive control), which had an $\mathrm{IC}_{50}$ of $28.0 \pm 14.31 \mu \mathrm{g} / \mathrm{mL}$, further endorsing the potent antioxidant activity of new MGGG.

\section{Reducing power assay}

The reducing power of phenolic compounds implicates its antioxidant activity. In the reducing power assay, the more antioxidant compounds convert the oxidation form of iron $\left(\mathrm{Fe}^{+3}\right)$ in ferric chloride to ferrous $\left(\mathrm{Fe}^{+2}\right)$. Fig. 4 showed that AEEE, MGGG and the isolated compounds (2-5) had concentrationdependent reducing power. MGGG showed the highest activity with a comparable reducing power to standard quercetin.

\section{In-vitro enzyme assays}

In the current study, AEEE and its isolated compounds exhibited anti- $\alpha$-amylase, $\beta$ - glucosidase, and pancreatic lipase activities (Table 2).

Table (2): Effect of different tested compounds in the three different enzyme inhibition assays. 


\begin{tabular}{|c|c|c|c|}
\hline \multicolumn{4}{|c|}{ a- Amylase inhibition at $300 \mu \mathrm{g} / \mathrm{mL}$} \\
\hline Tested compound* & $\%$ inhibition & $\mathrm{IC}_{50}$ & $P$ value \\
\hline AEEE & $89.02 \pm 2.31$ & $176.3 \pm 4.21$ & \\
\hline MGGG & $91.36 \pm 2.45$ & $157.54 \pm 5.9$ & $<0.0001$ \\
\hline Kaempferol 3-O-rutinoside & $78.04 \pm 1.15$ & $216.89 \pm 5.50$ & $<0.0001$ \\
\hline Quercetin 3-O-rutinoside & $78.92 \pm 4.13$ & $217.35 \pm 5.30$ & $<0.0001$ \\
\hline Tellimagranidine-I & $72.13 \pm 3.49$ & $223.6 \pm 3.90$ & $<0.0001$ \\
\hline $2,3-a, \beta$-digalloy glucose & $80.37 \pm 3.81$ & $206.89 \pm 5.60$ & $<0.0001$ \\
\hline Acarbose $300 \mathrm{ug} / \mathrm{mL}$ & $49 \pm 2.80$ & $230.85 \pm 3.70$ & $<0.0001$ \\
\hline \multicolumn{4}{|c|}{$\beta$-Glucosidase inhibition at $300 \mu \mathrm{g} / \mathrm{mL}$} \\
\hline AEEE & $88.13 \pm 1.25$ & $76.12 \pm 2.25$ & $<0.0001$ \\
\hline MGGG & $92.70 \pm 1.42$ & $72.77 \pm 2.67$ & $<0.0001$ \\
\hline Kaempferol 3-O-rutinoside & $66 \pm 3.47$ & $104 \pm 3.80$ & $<0.0001$ \\
\hline Quercetin 3-O-rutinoside & $68.43 \pm 2.30$ & $100.23 \pm 3.80$ & $<0.0001$ \\
\hline Tellimagranidine-I & $58.44 \pm 3.61$ & $115.21 \pm 4.90$ & $<0.0001$ \\
\hline $2,3-a, \beta$-digalloy glucose & $47 \pm 4.79$ & $140.33 \pm 5.20$ & $<0.0001$ \\
\hline Acarbose at $600 \mu \mathrm{g} / \mathrm{mL}$ & $58 \pm 2.30$ & $522 \pm 3.20$ & $<0.0001$ \\
\hline \multicolumn{4}{|c|}{ Pancreatic Lipase Inhibition at $100 \mu \mathrm{g} / \mathrm{mL}$} \\
\hline AEEE & $79 \pm 3.21$ & $45 \pm 5.11$ & \\
\hline MGGG & $87 \pm 2.38$ & $32 \pm 4.43$ & $<0.0001$ \\
\hline Kaempferol 3-O-rutinoside & $18.69 \pm 3.1$ & $265.95 \pm 4.71$ & $<0.0001$ \\
\hline Quercetin 3-O-rutinoside & $19.52 \pm 4.36$ & $270.1 \pm 6.20$ & $<0.0001$ \\
\hline Tellimagranidine-I & $35.81 \pm 3.84$ & $135.8 \pm 4.30$ & $<0.0001$ \\
\hline $2,3-a, \beta$-digalloy glucose & $82.17 \pm 2.53$ & $40.42 \pm 2.30$ & $<0.0001$ \\
\hline Orlistat $100 \mathrm{ug} / \mathrm{mL}$ & $81 \pm 4.5$ & $24.02 \pm 2.30$ & $<0.0001$ \\
\hline
\end{tabular}

Data are presented as $\%$ of inhibition \pm S.D. and $\mathrm{IC}_{50} \pm$ S.D.*: indicates significant difference in $\%$ of inhibition between AEEE and its isolated compounds. 


\section{Acute oral toxicity}

Oral administration of AEEE showed no signs of toxicity or mortality with no significant changes in neurological and behavior responses in any tested group during $72 \mathrm{~h}$ study up to $2000 \mathrm{mg} / \mathrm{kg}$ body weight of the extract, 250 and $500 \mathrm{mg} / \mathrm{kg}$ doses were selected for the antidiabetic studies.

\section{Effect of AEEE on body weight}

Treatment with AEEE at $500 \mathrm{mg} / \mathrm{kg}$ body weight significantly inhibited the reduction in the body weight induced by STZ compared to DC, Fig. 5.

\section{Effect of AEEE on liver and kidney functions' markers}

No significant changes in the liver and kidney functional tests were observed. After two weeks treatment diabetic groups treated with ( 250 or $500 \mathrm{mg} / \mathrm{kg}$ ) AEEE alleviated the hepatocellular caused by STZ by reduction in the levels of AST and ALT [32]. In addition, they reversed the high creatinine and urea levels. Moreover, administration of extract preserved the values of serum AST, ALT, urea and creatinine, thus illustrating its non-toxic nature, as shown in Fig. 6. AEEE showed insignificant changes in both liver and kidney functional tests with irrelevant alterations in all parameters under the present investigation.

\section{Effect of AEEE on serum blood glucose, insulin and a-amylase}

The serum glucose level of STZ-induced diabetic rats in groups IV and V remarkably decreased after administration of 250 and $500 \mathrm{mg} / \mathrm{kg}$ of AEEE, with increased insulin levels and reduced a amylase activity on comparison to the DC group. The percentage change from DC were as follows; $66.8 \%, 91.6 \%$, $44.7 \%, 69.8 \%, 158 \%$ and $50.7 \%$, respectively. Nevertheless, there was a significant difference between AEEE treated diabetic groups and glibenaclamide group $(\mathrm{VI})$ in all three measured parameters as shown in Fig. 7.

\section{Effect of AEEE on serum lipid profile}

TG, TC, and LDL-C levels expressed a notable reduction in diabetic groups treated with 250 and 500 $\mathrm{mg} / \mathrm{kg}$ of AEEE with an elevation in HDL-C levels relative to the $\mathrm{DC}$ group. The percentage changes from DC were as follows; $37.67,34.93,33.52,55.58,54.2,38.04,51.69$ and 58.98 , respectively. Furthermore, there was a significant difference between AEEE treated diabetic groups and the glibenaclamide group (VI) in all lipid profile parameters as shown in Fig. $\mathbf{8}$.

\section{Effect of AEEE on oxidative stress markers of pancreas}

Remarkable reduction in antioxidant enzyme activity (SOD) and a significant increase in TBARS manufacture in pancreatic tissues of DC group versus NC group Fig. 9. AEEE treated diabetic groups increased SOD activity and significantly suppressed the formation of TBARS on comparison to DC group. The percentage change from diabetic groups for the 250 and $500 \mathrm{mg} / \mathrm{kg}$ doses were; 71.6, 42.78, 80.9 
and 47.45, respectively. Furthermore, there was a significant difference between AEEE treated diabetic groups and glibenaclamide group (VI) in oxidative stress parameters Fig. 9.

\section{Effect of AEEE on pancreas histopathological examination}

Pancreas histopathological examination of NC, AE500-NC and AE250-NC groups showed normal picture Fig. 10 (A, b and C). Islets of Langerhans appears as circular shapes with normal cell lining, while the exocrine components and the interlobular duct surrounded with the supporting tissue appeared well organized and with normal morphology Fig. 10 (A and C). Image morphometry showed that the mean islets area in non-diabetic rats was $(145.21 \pm 3.49) \mathrm{mm}^{2}$, whereas for AE500-NC and AE250-NC groups were $(175.67 \pm 1.85)$ and $(167.89 \pm 1.34) \mathrm{mm}^{2}$, respectively. On the other hand, histopathological examination of diabetic rats showed the acinar cells with up normal morphology around the islets. The cells of islets were in degenerative form with asymmetrical vacuoles with intra islets hemorrhage, reduced size of islet cells and number of $\beta$-cells Fig. 10 ( $D$ and $E$ ). The diabetic rats mean islets area was (110.65 $\pm 9.41) \mathrm{mm}^{2}$ which in comparison with normal rats appeared smaller. Pancreas sections of AE500-DC and AE250-DC groups were microscopically investigated, suggesting the protection of the islets due to recovery of Langerhans' islets size with $\beta$-cells repair Fig. 10 ( $F$ and $G$ ). This regeneration of the $\beta$-cell was more obvious at higher dose, whereas with the mean of islets area for AE500-DC and AE250-DC groups were $(185.33 \pm 10.41)$ and $(180.12 \pm 6.52) \mathrm{mm}^{2}$, respectively.

\section{Discussion}

Nowadays searching for natural compounds that have both antidiabetic and antioxidant activities, with fewer side effects, is still challenging. Polyphenols, in particular flavonoids, are suggested as better therapeutic agents in the management of free radical mediated diseases particularly diabetes mellitus and its chronic complications due to their potent antioxidant activity which has been demonstrated by both in vitro and animal models studies [33]. They are hydroxylated phenolic substances and the hydroxyl group mediate their antioxidant effects by scavenging free radicals by chelating metal ions [34].

Flavonols the class of MGGG is a sub class of flavonoids, are effective as antioxidant and antidiabetic agents mostly depending on their chemical structure. Both, configuration and the total number of hydroxyl groups increased both activities and substantially regulate the mechanisms of radical scavenging [35] and antidiabetic effects. Thus, the total of hydroxyl groups, hydroxyl configuration, the catechol structure in the B ring, C-2-C-3 double bond, and C-4 ketonic functional group are the essential features in the manifestation of bioactivity of flavonoids especially for antidiabetic effect [36]. Myrecetin significantly improves insulin resistance besides antioxidant, anti-inflammatory, aldose reductase inhibitory actions [37].

$\mathrm{AE}$ is an annual herb that grows as a summer weed in rice fields. Despite the reported antidiabetic activity of other Ammannia species, there is no data in the literature on phytoconstituents, antidiabetic activity and, its mechanism of action. In the current study, phytochemical investigation of AEEE resulted in the 
isolation of unique acylated flavonoid, myricetin $3-0-\beta^{-4} C_{7^{-}}$(6"-O-galloyl glucopyranosid) $7-0-\beta^{-4} C_{7^{-}}$ glucopyranoside, along with four additional known phenolics. Significant antioxidant potential of AEEE, polyphenols $2-5$, and highest antioxidant potential exhibited by MGGG are recorded with $I C 5_{0} 2.37 \pm 0.56$, $2.01 \pm 0.23$ and $158.13 \pm 2.82 \mu \mathrm{g} / \mathrm{mL}$ in comparison to standard against DPPH, ORAC and ferrous reducing assay, respectively. Several reports showed that the radical scavenging capacities increased with an increase in the number of phenolic hydroxyl groups; this was observed for the three classes of isolated compounds: flavonoids, gallotannins and ellagitannins [38]. Moreover, the antioxidant activity increased as the number of galloyl units increased; however, it is not affected by their position and not influenced by the presence of a hemiacetal hydroxyl and the 4,6-0-HHDP groups. Also, the presence of two adjacent phenolic hydroxyl groups on the galloyl moiety is significant and this justified the higher antioxidant capacity of tellimagrandin-I compared to nilocitin and the potential of MGGG, Flavonoids with potent antioxidant activity were shown to be effective in management of diabetes [39].

Pancreatic amylase and intestinal glucosidase are crucial enzymes involved in glucose formation [40]. $\beta$ glucosidases catalyze the breakdown of alkyl and aryl- $\beta$-glycosides, disaccharides and short chain oligosaccharides with dual activities of hydrolysis and transglycosylation [41]. Therefore, the study of $\beta$ glucosidase enzyme inhibitors is important for treatment of type 2 diabetes [42]. However, the effect of inhibitors on $\beta$-glucosidase was illustrated barely. Phenolic and flavonoids content in roselle were responsible for the inhibitory activity $\alpha-/ \beta$-glucosidase. Pancreatic $\alpha$-amylase catalyses the first step in the starch breakdown. Suppression of intestinal a-amylase activity hinders the starch and oligosaccharides breakdown to monosaccharides before absorption, this results profound control of T2D. Acarbose an oral hypoglycemic agent, is used for the inhibition of a-amylase [43]. Flavonoids as myricetin, the core of the new isolate MGGG, luteolin, quercetin were potent inhibitors. In fact, pancreatic lipase plays a key role for triglyceride absorption in the small intestine. [44]. Thereby, the hindrance of triglycerides absorption by lipase inhibition is a main route for avoiding obesity and management of T2D. The commercial drug Orlistat strongly inhibits the activity of pancreatic lipase[45]. Pancreatic lipase inhibitory activity has been attributed to various types of phytochemicals, such as saponins, polyphenols and terpenes [46].

The in vitro enzymatic inhibition results showed that AEEE and all isolates 1-5 possessed antidiabetic and anti-obesity activity, based on inhibition of pancreatic lipase, $\beta$ - glucosidase and $\alpha$-amylase. Apart from compound $\mathbf{3}$ [47], AEEE and all isolates were first reported. Moreover, significant difference existed between AEEE and its isolates as shown in Table (2). It was reported that acylated flavonoids, the class of the new isolate MGGG and its core (myricetin), have been previously reported to have strong antidiabetic activity $[37,48]$. MGGG exhibited the highest \% of inhibition in all three enzyme assays with antidiabetic and anti-obesity properties higher than the reference standards Acarbose and Orlistate Table (2). Furthermore, there was a significant positive correlation between the phenolic and flavonoid contents of the extract and the $\alpha$-amylase, $\beta$-glucosidase and pancreatic lipase inhibition ( $r=0.97 P=0.007$ and $r=0.91 P=0.008)$ for $a$ amylase inhibition, $(r=0.93 P=0.006$ and $r=0.90 P=0.0073)$ for $\beta$-glucosidase 
inhibition and $(r=0.92 \mathrm{P}=0.005$ and $\mathrm{r}=0.91 \mathrm{P}=0.006)$ for pancreatic lipase inhibition demonstrating that the phenolics and flavonoids may be the main constituents in charge of the inhibitory effect of AEEE.

The docking results of MGGG with the digestive enzymes provided good information about the binding mode that aligned correctly with the in vitro experimental results. For instance, MGGG showed moderate to strong binding mode with Score (DG) range -7.01 to $-8.80 \mathrm{kcal} / \mathrm{mol}$. It was observed that MGGG was well accommodated inside the active site of all tested digestive enzymes, displaying a very good geometric complementation and excellent mapping which increase its inhibitory activity and was involved in various type of interactions with the active site residues of the target enzymes. In addition, in all tested enzymes MGGG showed RMSD value lower than $2.00 \AA$ which confirm its occupancy in the original site of crystal ligand and ensure the validation of molecular docking study. From the molecular structural point of view, actually, presence of multiple polar hydroxyl groups is very important for the stabilization of MGGG at the catalytic sites of the tested digestive enzymes due to the availability of the electron donating groups $(-\mathrm{OH})$ forming electronegative and electron cloud system inside the pocket that can do fitted stabilized interactions with polar and charged amino acids. This justify the higher inhibitory potential of MGGG compared to the used standard drugs towards digestive enzymes. In addition, docking results revealed that hydroxyl groups of the B-ring, galloylglucose and $\beta$-D-glucopyranose moieties are vital for its inhibition power and were the most critical groups for the stabilities in the active sites among the tested enzymes.

In fact, the interaction forces of the hydrogen bond are considered to play a critical role in

stabilizing the ligand-enzyme complex in order to exert catalytic reaction, which depend mainly on the number of hydrogen bonds, distance between hydrogen bonds donor/acceptor and attached amino acids in targeted pocket, DG free energy score and RMSD value should be lower than $2 \AA$. Therefore, in terms of binding energy and binding affinity and compared with the standards Orlistat and acarbose, MGGG showed higher binding free energies for all tested digestive enzymes, with the highest inhibitory activity against $\beta$-glucosidase $(D G=-8.98 \mathrm{kcal} \mathrm{mol})$ and the lowest inhibitory activity against pancreatic lipase $(D G=-7.01 \mathrm{kcal} \mathrm{mol})$. This is due to the polar nature of MGGG and the presence of some polar and nonpolar amino acids in the critical pocket of pancreatic lipase, so the region of non-polar amino acids is not fully occupied. The glucose level was significantly reduced and the insulin level was elevated after administration of AEEE as compared to DC group. The histopathological results further confirmed this, which demonstrate that the structural integrity of islets of Langerhans was recovered. Furthermore, they decreased a-amylase activity. Phenolics are reported to decrease the activity of digestive enzymes.[49,50] and this is full agreement with the in vitro assay and molecular docking results.

In this investigation, the abnormal serum lipid profile was established in diabetic rats. This result agrees with Pepato et al. and Sharma et al. [51, 52]. This abnormal serum lipid profile was inverted after incorporation of AEEE with both doses. Hence, the extract could be helpful in refining lipid metabolism which will in turn aid in the protection against different diabetic complications. 
AEEE treatment of diabetic groups significantly increased SOD activity and significantly inhibited the creation of TBARS when matched with the DC group. This may be attributed to its high phenolic and flavonoids and in agreement with the high in vitro antioxidant potential of both the extract and new isolate using DPPH, ORAC and ferrous reducing assays. Furthermore, AEEE was considered safe as they decreased the levels of AST, ALT, creatinine and urea compared to DC. The biochemical findings agree with histopathological modifications of $\beta$-cells of pancreas. Such histopathological modifications were decreases by incorporation of AEEE extract at both doses. The current study agrees with previous studies on antidiabetic and anti-obesity effects of herbal extracts $[53,54]$.

\section{Conclusion}

AEEE effectively improved hyperglycemia, lipid profile while obstructing the advancement of oxidative stress in diabetic group with no signs of toxicity. In addition, histopathological investigations demonstrated the decrease in the pancreas damage and went along with the biochemical findings. This result obviously indicated the efficacy of AEEE and MGGG in the dual management of T2D and obesity. In addition, proposes antioxidant activity, inhibition of digestive enzyme actions and in vivo antidiabetic activity as possible paths of $A E$ in the treatment of $T 2 D$ and obesity. This encourages further investigations on AEEE to discover its mechanism of action on the molecular level and to launch its prospective in the prophylaxis and/or cure of diabetes and obesity.

\section{Materials And Methods}

\section{General}

Solvents for paper chromatography: (1) $\mathrm{H}_{2} \mathrm{O}$; (2) $2 \% \mathrm{HOAc}$ (acetic acid: $\left.\mathrm{H}_{2} \mathrm{O}, 98: 2\right)$; (3) BAW (n-BuOH$\mathrm{HOAc}-\mathrm{H}_{2} \mathrm{O}, 4: 1: 5$, upper layer); (4) B BPW (Benzene- $n$-BuOH-Pyridine- $\mathrm{H}_{2} \mathrm{O}, 1: 5: 3: 3$, upper layer). Chemical materials: All chemicals were from Sigma-Alldrich (Merck, USA). Shimadzu UV-Visible-1601 spectrophotometer for measuring UV. HRESI mass spectra were recorded on Finnigan LTQ FT Ultra mass spectrometer (Thermo Fisher Scientific, Bremen, Germany). NMR spectroscopical analysis was performed on Brucker $400 \mathrm{MHz}$ NMR spectrometer, at $400 \mathrm{MHz}[55]$.

\section{Plant materials}

Aerial parts of AE were collected during the flowering stage in Spetamber, 2018 from rice field, Benha district, Qalubia governorate, Egypt. Voucher specimen (3468) was deposited in Herbarium of Flora and Phytotaxonomy Researches Department (CAIM), Horticultural Research Institute, Agricultural Research Center, Giza, Egypt. The identity of which was verified by Prof. Dr. Abdel-Haleem Abdel-Mogaly, Prof. of Botany at Agricultural Research Centre.

\section{Preparation of AEEE}


Aerial parts of $A E(2.5 \mathrm{~kg})$ were extracted by being refluxed with $\mathrm{EtOH} / \mathrm{H}_{2} \mathrm{O}(3: 1,3$ times, each with $3 \mathrm{~L}$, for $8 \mathrm{~h}$, under reflux). The solvent was removed under reduced pressure at $50{ }^{\circ} \mathrm{C}$ to yield dark brown amorphous material $(150 \mathrm{~g})$.

\section{Estimation of total phenolic and flavonoid contents}

Folin-Ciocalteu reagent was used for measuring phenolic content and estimated as gallic acid equivalents (GAE) per g of sample. Aluminium chloride $\left(\mathrm{AlCl}_{3}\right)$ used for measuring total flavonoid content (colorimetric assay and estimated as catechin equivalents (CE) per g of sample using [55].

\section{Isolation and identification of phenolics (1-5)}

A portion of AEEE $(70 \mathrm{~g})$ was applied to a Sephadex LH 20 column $(480 \mathrm{~g})$ and eluted with $\mathrm{H}_{2} \mathrm{O} / \mathrm{MeOH}$ mixtures of decreasing polarity to yield 7 major fractions (I - VII). Fraction I eluted with $\mathrm{H}_{2} \mathrm{O}$; II with $20 \%$, III with $40 \%$, IV with $50 \%$, V with $70 \%$, VI with $80 \%$, VII with $90 \%$. The collected fractions were individually subjected to two-dimensional paper chromatography (2DPC).

Compound 1 (77 $\mathrm{mg})$ was isolated pure from fraction II $(1.8 \mathrm{~g})$ by repeated column fractionation over $\mathrm{MCl}$ gel (CHP-20P, 75-150 mm; Mitsubishi Chemical Co., Düsseldorf, Germany) using MeOH/ $\mathrm{H}_{2} \mathrm{O}$ mixture (20\%) for elution. Compound $\mathbf{2}(88 \mathrm{mg})$ and $\mathbf{3}(64 \mathrm{mg})$ were individually separated from fraction IV (9.21 g) by $\mathrm{MCl}$ gel column fractionation, using $\mathrm{H}_{2} \mathrm{O}$ as solvent, followed by preparative paper chromatography (Prep. PC), using BAW as solvent. Compound $\mathbf{4}(79 \mathrm{mg})$ was purely isolated from $1.1 \mathrm{~g}$ of fraction $\mathrm{V}$ by applying repeated Sephadex $\mathrm{LH}-20$ column fractionation and elution with $\mathrm{H}_{2} \mathrm{O}-\mathrm{EtOH}$ (30:70) mixture. Compound $\mathbf{5}(89 \mathrm{mg})$ was obtained from fraction VII $(3.35 \mathrm{~g})$ through fractionation over polyamide column and elution with a mixture of $\mathrm{MeOH}-\mathrm{C}_{6} \mathrm{H}_{6}-\mathrm{H}_{2} \mathrm{O}$ (60:38:2).

\section{Myricetin-3-0- $\beta^{4}{ }^{4} C_{1}-\left(6\right.$ "-O-galloyl glucopyranoside)-7-0- $\beta^{-4} C_{7}$ glucopyranoside, MGGG, new compound 1}

UV: $\lambda_{\max }(\mathrm{MeOH}),(\mathrm{nm}): 256,356 ;+\mathrm{NaOAc}: 257,358 ;+\mathrm{NaOAc}_{3} \mathrm{H}_{3} \mathrm{BO}_{3}: 268,390 ;+\mathrm{AlCl} 3: 269,395 ;+\mathrm{AlCl} 3$ +HCl: 271, 303, 401; NaOME: 253, $404 \mathrm{~nm}$. ESI MS (negative mode): $\mathrm{m} / \mathrm{z}=:$ [M-H] ${ }^{-}$. Negative ESIMS: negative mass spectrum: $[\mathrm{M}-\mathrm{H}]^{-}$ion at $\mathrm{m} / \mathrm{z}=631, \mathrm{Mr}=632$ Dalton. $\beta$-Glucosidase enzymatic hydrolysis yielded myricetin-3-O- $\beta$-(6"-galloyl glucoside): UV $\lambda_{\max } \mathrm{MeOH}$ : 260,268, 295 (inflection), 356; +NaOMe:

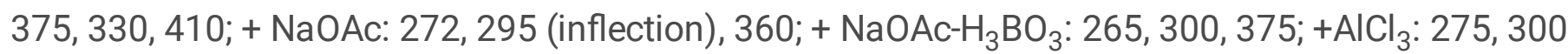
(inflection), 425; + $\mathrm{AlCl}_{3}-\mathrm{HCl}: 274,298$ (inflection), 404. ${ }^{1} \mathrm{H}-\mathrm{NMR}: 6.16$ (d, J=2 Hz, H-6), 6.32 (d, J=2 Hz, H8), 7.5 (s, H2' \& H-6'), 5.28 (1H, d, J=8 Hz, H-1"), 4.28 (I H, d, J=12 Hz, H-6"a), 4.02 (I H, m, H-6"b), 3.22-3.9, glucoside protons overlapped with hydroxyl and water protons), $6.98\left(\mathrm{~s}, \mathrm{H}-2^{\mathrm{m} " \prime \prime}\right.$ and $\mathrm{H}-6 \mathrm{6}$ "'). ${ }^{1} \mathrm{H}$ NMR of 1 : 6.3 (d, J=2.5 Hz, H-6), 6.75 (d, J=2.5 Hz, H-8), 7.43 (s, 2H, H-2' \& H-6'), 5.35 (d, J=8.5 Hz, H-1"'), 5.02 (d, $J=8.5 \mathrm{~Hz}, \mathrm{H}-1$ "), 4.26 (d, J=12 Hz, H-6"b), 4.12 (m, H-6"a). ${ }^{13} \mathrm{C}$ NMR: Myricetin moiety: 156.9 (C-2), 134.4 (C-3), 177.6 (C-4), 1560.8 (C-5), 99.2 (C-6), 161.6 (C-7), 94.6 (C-8), 156. (C-9), 104.5 (C-10), 121.2 (C-1'),

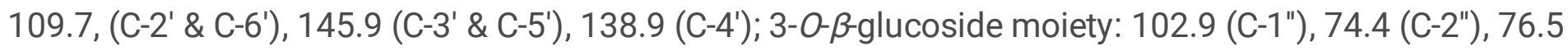
(C-3"), 69.8 (C-4"), 76.6 (C-5"), 63.3 (C-6"); 7-0- $\beta$-glucoside moiety: 99.3 (C-1"'), 73.2 (C-2"'), 77.2 (C-3"'), 
69.5 (C-4"'), 76.9 (C-5"'), 60.16 (C-6"'); galloyl moiety: 121.9 (C-1"''), 109.7 (C-2"'" \& C-6"'"'), 145.5 (C-3"'"\& C-5' "'), $1356.8\left(\mathrm{C}-4^{\prime \prime \prime \prime}\right)$.

\section{Molecular Modelling}

The docking analysis was performed by using MOE 2015 software. The binding sites were generated from the co-crystallized ligands, within crystal protein (PDB codes: 2QV4 - 2ZOX -2OXE). To prepare the protein for the docking experiments, water molecules were removed. The crystallographic disorders and unfilled valence atoms were corrected, using protein report and utility and clean protein options. The protein geometry was corrected by applying CHARMM and MMFF94 force fields. The rigidity of binding site was obtained by applying fixed atom constraint. The active site essential amino acids were defined and prepared for docking process. The structures of tested compounds (ligands) were imported as MDLSD file format. The 3D structures of the ligands were prepared for docking by first protonated, then their energy was minimized by applying $0.05 \mathrm{RMSD} \mathrm{kcal} / \mathrm{mol}$ using CHARMM force field. The Molecular docking processes process was carried out using CDOCKER protocol. The receptor was held rigid while the ligands were allowed to be flexible during the refinement each molecule was allowed to produce ten different interaction poses with the protein. The docking scores (-CDOCKER interaction energy) of the best-fitted poses with the active sites at the tested enzymes were recorded. The output from of MOE was further analyzed with Discovery Studio 2.5 software. These processes were used to predict the proposed binding mode, affinity, preferred orientation of each docking pose and binding free energy $(\Delta G)$ of the tested compound with pancreatic a-amylase, intestinal $\beta$-glucosidase and pancreatic lipase [56].

\section{In-vitro studies}

\section{DPPH assay}

The assay was carried out for AEEE and isolated phenolics according to Brand-Williams et al.[57].

\section{Oxygen radical absorbance capacity (ORAC assay)}

The antioxidant assay was applied on AEEE and isolated phenolics [58].

\section{Reducing power assay}

The assay was carried out on AEEE and isolated phenolics [59].

\section{a-Amylase inhibition}

The assay was implemented in accordance with $[53,60]$. The percentage of inhibition can be estimated using the following equation.

\section{B-Glucosidase inhibition}

The assay was done in conformity with $[61,62]$ and using the same formula for amylase. 


\section{Pancreatic lipase inhibition}

Determination of \% inhibition of pancreatic lipase was calculated as prescribed by Hegazi [53] and using the same formula for amylase.

\section{In-vivo studies}

\section{Experimental animals}

Male Sprague-Dawley rats (170-220 g) were acquired from the National Research Centre (NRC, Giza, Egypt). Animals were acclimatized in our animal facility for one week before the experiment. Animals had total access to standard laboratory food pellets and water ad libitum under temperature-controlled conditions and $12 \mathrm{~h}$ light-dark cycles. The animal experiments were conducted according to the international regulations of the usage and welfare of laboratory animals and were approved by the Ethics Committee of the National Research Centre, Cairo, Egypt, Protocol number 49/261 (2019).

\section{Acute oral toxicity}

The acute oral toxicity of AEEE was adpoted in male Sprague-Dawley rats according to OECD guideline No.423 (OECD, 2001). Based on a pilot study in our laboratories, limit test was performed. Animals were fasted overnight and the extract was administered orally using gastric feeding needle at a dose of $2000 \mathrm{mg} / \mathrm{kg}$ (10 mL/kg dosing volume) [63].

\section{Induction of diabetes}

Induction of diabetes was done by a single intraperitoneal injection of streptozotocin (STZ) solution dissolved in freshly prepared citrate buffer $(0.1 \mathrm{~mol} / \mathrm{L}, \mathrm{pH} 4.5)$ at a dosage of $60 \mathrm{mg} / \mathrm{kg}$. After $72 \mathrm{~h}$ tail vein blood was collected to determine fasting blood glucose level colorimetrically (Diamond Diagnostics, Cairo, Egypt). Glucose levels over $200 \mathrm{mg} / \mathrm{dL}$ were considered diabetic and included in the study.

\section{Experimental design}

Male Sprague-Dawley were randomly divided into 6 groups, comprising six rats each as follows; Group I: Normal control rats (NC). Group II: Normal rats treated with AEEE (500 mg/kg) (AE 500-NC). Group III: Diabetic control (DC). Group IV: Diabetic rats treated with AEEE (250 mg/kg) (AE250-DC). Group V: Diabetic rats treated with AEEE (500 mg/kg) (AE500-DC). Group Vl: Diabetic rats treated with standard drug glibenclamide $(0.25 \mathrm{mg} / \mathrm{kg})$. Groups I and III received only the vehicle (distilled water). Administration of different oral doses of AEEE started $72 \mathrm{~h}$ after STZ injection. This was done using an intragastric tube to the treated group daily till the experiment ended. Weight measurement was done at the beginning of the study and at the end of the 28 th day Doses were chosen based on previous literature [49].

\section{Blood and tissue sampling}


FBG was measured 14 and $28 \mathrm{~d}$ after treatment. After the 28th day, blood samples were taken from the retro-orbital venous plexus under light ether anesthesia after overnight fasting. Pancreatic tissues were dissected. They were washed in ice-cold saline solution immediately. After that they were divided into two portions. One was homogenized in $0.1 \mathrm{~mol} / \mathrm{L}$ potassium phosphate buffer ( $\mathrm{pH} \mathrm{7.4)} \mathrm{using} \mathrm{Tissue} \mathrm{master}$ TM125 (Omni International, USA). After centrifugation at $3000 \mathrm{r} / \mathrm{min}$ for $10 \mathrm{~min}$, the clear supernatant was kept at $-80^{\circ} \mathrm{C}$ for biochemical assays. The second portion was placed in $10 \%$ formalin for histopathological investigation [64].

\section{Assay of Biomarkers}

\section{Determination of liver and kidney functions markers}

Serum aspartate transaminase (AST), alanine transaminase (ALT), serum urea and creatinine level were measured as kidney function tests using kits provided by Spectrum Diagnostics Company, (Egypt). The operational processes were measured in accordance with the kit instructions.

\section{Determination of insulin and a-amylase activity}

Insulin level was determined using ELISA kit (CUSABIO, Wuhan, China). $\alpha$-amylase activity was assessed by (ELitech Clinical Systems, Sèes France).

\section{Measurement of serum lipid profile}

Triacylglycerol (TAG), total cholesterol (TC), and high-density lipoprotein cholesterol (HDL-C) were assayed colorimetrically using (Reactivos GPL,Barcelona, Spain ). Low-density lipoprotein cholesterol (LDL-C) was calculated from TAG and HDL-C values according to Friedewald's formula [65]:

\section{Determination of oxidative stress markers in pancreatic tissue}

Superoxide dismutase activity (SOD) was estimated in accordance with Minami and Yoshikawa [66]. Lipid peroxidation was measured using thiobarbituric acid reactive substances (TBARS) colorimetrically [67].

\section{Histopathological investigation}

Histopathologic examination was performed by light microscopy on pancreas specimen fixed in $10 \%$ formalin. After fixation, the samples were processed to obtain $5 \mu \mathrm{m}$ thick paraffin sections followed by staining with hematoxilin and eosin $(\mathrm{H} \& \mathrm{E})$ then observation under a Leica photomicroscope.

\section{Image morphometry}

The morphometric analysis was performed at the Pathology Department, National Research Center using the Leica Qwin 500 Image Analyzer (LEICA Imaging Systems Ltd., Cambridge, England) which consisted 
of Leica DM-LB microscope with JVC color video camera attached to a computer system Leica Q 500IW E stained slide. The results were expressed in $\left(\mu \mathrm{m}^{2}\right)$ with the mean of standard deviations (SD) [68].

\section{Statistical Analysis}

The results are expressed as mean of standard deviations (SD). The differences among the various groups were analyzed using a one-way analysis of variance (ANOVA) followed by Tukey's post hoc test. The level of significance was taken at $p$ values $\leq 0.05$. All analyses were done using the SPSS ver. 25.0 (IBM, Chicago, USA). GraphPad prism ${ }^{\circledR}$ software (version 6.00 for Windows) was implemented.

\section{Declarations}

\section{Author contributions}

N.S. and E.M. designed the study, methodology, validation, wrote main manuscript, and prepared the tables and figures. R.R. Methodology. M.A.M.N. validation. All authors revised the manuscript.

\section{Additional information}

Funding: This research received no external funding.

Competing interests: The authors declare no competing interests

\section{Availability of materials and data}

Supporting data are available

\section{References}

1. Stenfen Ma., et al. Associations of diabetes milletus andethinicity with mortality in a multiethnic Asaian population: data from the 1992 Singapore National Health Survey. Am. J. Epidemiol. 158, 543-552 (2003). https://doi.org/10.1093/aje/kwg199.

2. IDF, Diabetes Atlas: Update of mortality attributable to diabetes for the IDF Diabetes Atlas: Estimates for the year 2013. Diabetes Res. Clin. Pract. 109 (3), 461-465 (2014.) https://doi.org/10.1016/j.diabres.2016.04.016.

3. DK., P., R., K., Prasad SK., SairamK., \& S., H. Anti-diabetic and in vitro antioxidant potential of Hybanthus enneaspermus (Linn) F. Muell in streptozotocin-induced diabetic rats. Asian Pac. J. Trop. Biomed. 1(4), 316-322 (2011). https://doi.org/10.1016/S2221-1691(11)60051-8.

4. Punthakee, Z., Goldenberg, R., \& Katz, P. Definition, classification and diagnosis of diabetes, prediabetes and metabolic syndrome. Can. J. Diabetes. 42, 10-15 (2018). https://doi.org/10.1016/j.jcjd.2017.10.003. 
5. Lacroix, I. M. E., \& Li-Chan, E. C. Y. Overview of food products and dietary constituents with antidiabetic properties and their putative mechanisms of action: a natural approach to complement pharmacotherapy in the management of diabetes. J. Mol Nutr Food Res. 58, 61-78 (2014). https://doi.org/10.1002/mnfr.201300223.

6. Eckel, R., et al. Obesity and Type 2 Diabetes: What Can Be 82 Unified and What Needs to Be Individualized?. Diabetes Care, 34(6), 1424-1430 (2011). https://doi.org/10.1210/jc.2011-0585.

7. Kumar, P.J., \& Clark, M.Textbook of Clinical Medicine. London (Saunders publishers, 2002).

8. Bastaki, S. Review-diabetes milletus and its treatment. INT. J. Diabetes Metab. 13, 111-134 (2005).

9. Wais, M., et al. Herbal drugs for diabetic treatment: an updated review of patents. Recent Pat Antiinfect Drug Discov. 7(1), 53-59 (2012). https://doi.org/10.2174/157489112799829701.

10. Carek, P. J., \& Dickerson, L. M. Current concepts in the pharmacological management of obesity. J. Drug. 57, 883-904. (1999). https://doi.org/10.2165/00003495-199957060-00005.

11. Yang, H., Jin, X., Kei Lam, C. W., \& Yan, S. K. Oxidative stress and diabetes mellitus. Clin Chem Lab Med. 49(11), 1773-1782 (2011). https://doi.org/10.1515/cclm.2011.250.

12. Savu, 0. , et al. Increase in total antioxidant capacity of plasma despite high levels of oxidative stress in uncomplicated type 2 diabetes mellitus. J Int Med Res. 40(2), 709-716 (2012). https://doi.org/10.1177/147323001204000235.

13. Patel, D. K., Kumar, R., Laloo, D., \& Hemalatha, S. Diabetes mellitus: an overview on its pharmacological aspects and reported medicinal plants having antidiabetic activity. Asian Pac $\mathrm{J}$ Trop Biomed. 2(5), 411-420 (2012). https://doi.org/10.1016/S2221-1691(12)60067-7.

14. Hussain, T., et al. Oxidative Stress and Inflammation: What Polyphenols Can Do for Us?. J. Oxid Med Cell Longev 2016. 1-9 (2016). https://doi.org/10.1155/2016/7432797.

15. Sekhon-Loodu, S., \& Rupasinghe, H. P. V. Evaluation of Antioxidant, Antidiabetic and Antiobesity Potential of Selected Traditional Medicinal Plants. J. Front Nutr. 6, 53 (2019). https://doi.org/10.3389/fnut.2019.00053.

16. Nawwar, M., et al. Acylated flavonol diglucosides from Ammania auriculata. Z Naturforsch C J Biosci. 70(1-2), 39-43 (2015). https://doi.org/10.1515/znc-2014-4165.

17. Boulos, L. Flora of Egypt: Geraniaceae-Boraginaceae (ed. 2). (Al Hadara Publ, Cairo 2000).

18. Tackholm, V. Students' Flora of Egypt (ed. 2) P.423 (Cairo University Press, Cairo, Egypt, 1974).

19. Awad, A. Pharmacognostical study of certain plants belonging to the family Lythraceae growing in Egypt. 304-315 (Mansoura university, Egypt 2010).

20. Patel, B., \& Kori, M. Antidiabetic Effect of Ammania baccifera Linn leaf on Streptozotocin Induced Diabetes in Male Albino Wistar Rats. RJPT. 11(11), 4773-4780 (2018). https://doi.org/10.5958/0974360X.2018.00869.7.

21. Dehaghani, Z. A., Asghari, G., \& Dinani, M. S. Isolation and identification of nicotiflorin and narcissin from the aerial parts of Peucedanum aucheri Boiss. J. Agric. Sci. Technol. A. 7, 45-51 (2017). https://doi.org/10.17265/2161-6256/2017.01.007. 
22. Akkol, E. K., et al. Bioassay-guided isolation and characterization of wound healer compounds from Morus nigra L.(Moraceae). Rec. Nat. Prod. 9(4), (2015). Corpus ID: 30601433.

23. Nawwar, M. A., et al. Polyphenols in Ammania auriculata: structures, antioxidative activity and cytotoxicity. J. Pharmazie. 69(11), 860-864 (2014). https://doi.org/10.1691/ph.2014.4635.

24. Harborne, J., \& William, C. The Flavonoids: Chapman and Hall. J. Biochemical systematics of flavonoids. 1056-1095 (1975). https://doi.org/10.1007/978-1-4899-2915-0.

25. Mabry, T. J., Markham, K., \& Thomas, M. The Systematic Identification of Flavonoids. 3-15 (Springer, New York. 1970) https://doi.org/10.1007/978-3-642-88458-0.

26. Markham, E., \& Geiger, H. H1 NMR Spectroscopy of flavonoids and their glycosides in hexadeuterodimethylsulfoxide. (ed. Harborne, J.B.) 676 (Chapman and Hall, London, 1994). https://doi.org/10.1201/9780203736692.

27. Markham, K., Ternai, B., Stanley, R., Geiger, H., \& Mabry, T. Carbon-13 NMR studies of flavonoids-III: Naturally occurring flavonoid glycosides and their acylated derivatives. J. Tetrahedron. 34(9), 13891397 (1978). https://doi.org/10.1016/0040-4020(78)88336-7.

28. Williams, L. K., Li, C., Withers, S. G., \& Brayer, G. D. Order and disorder: differential structural impacts of myricetin and ethyl caffeate on human amylase, an antidiabetic target. J. Med. Chem. 55(22), 10177-10186 (2012). https://doi.org/10.1021/jm301273u.

29. Jhong, C. H., Riyaphan, J., Lin, S. H., Chia, Y. C., \& Weng, C. F. Screening alpha-glucosidase and alphaamylase inhibitors from natural compounds by molecular docking in silico. J. Biofactors. 41(4), 242251 (2015). https://doi.org/10.1002/biof.1219.

30. Qi, Y., Zhao, Y., Lu, H., Wang, X., \& Jin, N. Comparative analysis of the bonding modes between two antidiabetic drugs with beta-glucosidases from different species. Indian J. Pharm. Sci. 78(4), 512524 (2016). https://doi.org/10.4172/pharmaceutical-sciences.1000146.

31. Zhang, X., Jia, Y., Ma, Y., Cheng, G., \& Cai, S. Phenolic composition, antioxidant properties, and inhibition toward digestive enzymes with molecular docking analysis of different fractions from Prinsepia utilis royle fruits. J. Molecules. 23(12), 3373 (2018).

https://doi.org/10.3390/molecules23123373.

32. Moulisha B, et al. Hepatoprotective activity of Terminalia arjuna leaf against paracetamol-induced liver damage in rats. Asian J Chem. 23, 1739-1742 (2011). https://doi.org/10.1016/S19957645(11)60127-2.

33. AL-Ishaq, R. K., et al. Flavonoids and their anti-diabetic effects: cellular mechanisms and effects to improve blood sugar levels. Biomolecules. 9(9), 430 (2019). https:// doi.org/10.3390/biom9090430.

34. Kumar, S., Mishra, A., \& Pandey, A. K. Antioxidant mediated protective effect of Parthenium hysterophorus against oxidative damage using in vitro models. J. BMC Complement Altern. Med. 13(1), 120 (2013). https://doi.org/10.1186/1472-6882-13-120.

35. Teissedre, P. L., Frankel, E. N., Waterhouse, A. L., Peleg, H., \& German, J. B. Inhibition of In vitrohuman LDL oxidation by phenolic antioxidants from grapes and wines. J. Sci. Food Agric. 70(1), 55-61 (1996). https://doi.org/10.1002/(SICI)1097-0010(199601)70:1<55::AID-JSFA471>3.0.C0;2-X. 
36. Sarian, M. N., et al. Antioxidant and antidiabetic effects of flavonoids: A structure-activity relationship based study. J. Biomed Res. Int. (2017). https://doi.org/10.1155/2017/8386065.

37. Li, Y., \& Ding, Y. Minireview: Therapeutic potential of myricetin in diabetes mellitus. J. Food Sci. Hum. Wellness. 1(1), 19-25 (2012). https://doi.org/10.1016/j.fshw.2012.08.002.

38. Fortes, G. A. C., et al.. Antioxidant activities of hydrolysable tannins and flavonoid glycosides isolated from eugenia uniflora L. Rec. Nat. Prod. 9(2), 251 - 256 (2015). Corpus ID: 55932328

39. Ceriello, A. Oxidative stress and glycemic regulation. J. Metab. 49(2), 27-29. (2000). https://doi.org/10.1016/S0026-0495(00)80082-7.

40. Abeysekera, W. K. S. M., et al. Amylase and glucosidase enzyme inhibitory activity of Ginger (Zingber Roscoe) an in vitro study. J. Sustain. Trop. Agric. Res. 19, 128-135 (2007). https://orcid.org/00000003-0947-6083.

41. Parizadeh, H., \& Garampalli, R. H. Evaluation of Some Lichen Extracts for $\beta$-Glucosidase Inhibitory as a Possible Source of Herbal Anti-diabetic Drugs. Am J Biochem. 6(2), 46-50 (2016). https://doi.org/10.5923/j.ajb.20160602.04.

42. Sánchez, M. A., García, S. K., May, P. F., \& Pea, L. M. R. Evaluation of biological activity of crude extracts from plants used in Yucatecan traditional medicine Part I. Antioxidant,antimicrobial and $\beta$ glucosidase inhibitory activities. J. Phytomedicine. 101(7), 633-649 (2001). https://doi.org/10.1078/0944-7113-00020.

43. Mogale, M., Lebelo, S. L., Thovhogi, N., De Freitas, A., \& Shai, L. a-Amylase and a-glucosidase inhibitory effects of Sclerocarya birrea [(A. Rich.) Hochst.] subspecies caffra (Sond) Kokwaro (Anacardiaceae) stem-bark extracts. Afr. J. Biotechnol. 10(66), 15033-15039 (2011). https://doi.org/10.5897/AJB11.1408.

44. Lowe, M. E. " Pancreatic triglyceride lipase and colipase: Insights into dietary fat digestion. J. Gastroenterol. 107, 1524-1536 (1994). https://doi.org/10.1016/0016-5085(94)90559-2.

45. Schnee, D. M., Zaiken, K., \& McCloskey, W. W. An update on pharmacological treatment of obesity. Curr Med Res Opin 22, 1462-1474 (2006). https://doi.org/10.1185/030079906X115496.

46. Birari, R. \& Bhutani, K. Pancreatic lipase inhibitors from natural sources: unexplored potential. Drug Discov Today. 12, 879-889 (2007). https://doi.org/10.1016/j.drudis.2007.07.024.

47. Oboh, G., Ademosun, A. O., Ayeni, P. O., Omojokun, O. S., \& Bello, F. Comparative effect of quercetin and rutin on a-amylase, a-glucosidase, and some pro-oxidant-induced lipid peroxidation in rat pancreas. Comp Clin Path. 24(5), 1103-1110 (2015). https://doi.org/10.1007/s00580-014-2040-5.

48. Lee, S.-S., Lin, H.-C., \& Chen, C.-K. Acylated flavonol monorhamnosides, a-glucosidase inhibitors, from Machilus philippinensis. J. Phytochem. 69(12), 2347-2353 (2008). https://doi.org/10.1016/j.phytochem.2008.06.006.

49. Hassan, S. K., et al. Hypoglycemic and antioxidant activities of Caesalpinia ferrea Martius leaf extract in streptozotocin-induced diabetic rats. Asian Pac. J. Trop. Biomed. 5(6), 462-471 (2015). https://doi.org/10.1016/j.apjtb.2015.03.004. 
50. Tundis R, Loizzo MR, \& F., M. Natural products as alpha amylase and alpha-glucosidase inhibitors and their hypoglycaemic potential in the treatment of diabetes: an update. Mini Rev Med Chem 10(4), 315-331 (2010). https://doi.org/10.2174/138955710791331007.

51. Pepato MT, et al. Fruit of the jambolan tree (Eugenia jambolana Lam.) and experimental diabetes. $J$ Ethnopharmacol. 96(1-2), 43-48 (2005). https://doi.org/10.1016/j.jep.2004.07.029.

52. Sharma B, Balomajumder C, \& P., R. Hypoglycemic and hypolipidemic effects of flavonoid rich extract from Eugenia jambolana seeds on streptozotocin induced diabetic rats. Food Chem Toxicol. 46(7), 2376-2383 (2008). https://doi.org/10.1016/j.fct.2008.03.020.

53. Hegazi, N. M., Radwan, R. A., Ali, S. M., \& Saad, H. H. "Molecular networking aided metabolomic profiling of beet leaves using three extraction solvents and in relation to its anti-obesity effects. J. Adv. Res. 4, 545-555 (2020). https://doi.org/10.1016/j.jare.2020.06.001.

54. Abdel-Rahman, R. F., et al. Ficus deltoidea extract down-regulates protein tyrosine phosphatase 1B expression in a rat model of type 2 diabetes mellitus: a new insight into its antidiabetic mechanism. J. Nutr. Sci. 9, (2020). https://doi.org/10.1017/jns.2019.40.

55. Mostafa, E. S., Nawwar, M. A., Mostafa, D. A., Ragab, M. F., \& Swilam, N. Karafsin, a unique monoacylated flavonoid apiofurnoside from the leaves of Apium graveolens var. secalinum Alef: In vitro and in vivo anti-inflammatory assessment. Ind Crops Prod. 158, 112901 (2020). https://doi.org/10.1016/j.indcrop.2020.112901

56. Al-Janabi, A.S., Al-Samrai, O.a.A., \& Yousef, T.A. New palladium (II) complexes with 1-phenyl-1Htetrazole-5-thiol and diphosphine Synthesis, characterization, biological, theoretical calculations and molecular docking studies. Appl. Organomet.Chem. 34(12), e5967 (2020). https://doi.org/10.1002/aoc.5967.

57. Brand-Williams, W., Cuvelier, M., E. \& Berset, C. Use of a free radical method to evaluate antioxidant activity. LWT-Food science and Technology 28(1), 25-30 (1995). https://doi.org/10.1016/S00236438(95)80008-5.

58. Lucas-Abellán, C., et al. ORAC-fluorescein assay to determine the oxygen radical absorbance capacity of resveratrol complexed in cyclodextrins. J. Agric. Food Chem. 56(6), 2254-2259 (2008). https://doi.org/10.1021/jf0731088.

59. Yen, G. C., \& Duh, P. D. Scavenging effect of methanolic extracts of peanut hulls on free-radical and active-oxygen species. J. Agric. Food Chem. 42(3), 629-632 (1994). https://doi.org/10.1021/jf00039a005.

60. Miller, G. L. Use of dinitrosalicylic acid reagent for determination of reducing sugar. J. Anal. Chem 31, 426-428 (1959). https://doi.org/10.1021/ac60147a030.

61. Grover, A. K., Macmurchie, D. D., \& Cushley, R. J. Characteristics of $\beta$-Glucosidase from almond. Biochim.Biophys.Acta. 482 (1), 98-108 (1977). https://doi.org/10.1016/0005-2744(77)90358-8.

62. Hash, J. H., \& King, K. W. Some properties of an aryl- $\beta$ glucosidase from culture filtrates of myrothecium verrucaria. J.Biol.Chem. 232(1), 395-402 (1958). https://doi.org/10.1042/bj0830331. 
63. Shoieb, S.M., Esmat, A., Khalifa A. E., \& Abdel-Naim A. B. Chrysin attenuates testosterone-induced benign prostate hyperplasia in rats. Food Chem. Toxicol. 111, 650-659 (2018). https://doi.org/10.1016/j.fct.2017.12.017.

64. Hassan, S.K., et al. Flavonoids-rich Extract of Beta vulgaris Subsp cicla L. var. Flavescens Leaf, a Promising Protector Against Gentamicin-induced Nephrotoxicity and Hepatotoxicity in Rats. Int. J. Pharmacol. 14(5), 652-666 (2018). https://scialert.net/abstract/?doi=ijp.2018.652.666.

65. Fukuyama, N., et al. Validation of the Friedewald Equation for Evaluation of Plasma LDL-Cholesterol. J. Clin. Biochem. Nutr. 43, 1-5 (2008). https://doi.org/10.3164/jcbn.2008036.

66. Minami, M., \& Yoshikawa, H. A simplified assay method of superoxide dismutase activity for clinical use. J. Clin Chim Acta. 92(3), 337-342 (1979). https://doi.org/10.1016/0009-8981(79)90211-0.

67. Lefevre, G., et al. Evaluation of lipidperoxidation by measuring thiobarbituric acid reactive substances. J. Ann Biol Clin Paris. 56(3), 305-319 (1998). PMID: 9754263.

68. Abd El-Aal, A.A., et al. Genomic instability in complicated and uncomplicated Egyptian schistosomiasis haematobium patients. Mol. Cytogenet. 8(1), 1-11. (2015). https://doi.org/10.1186/s13039-014-0104-5.

\section{Figures}

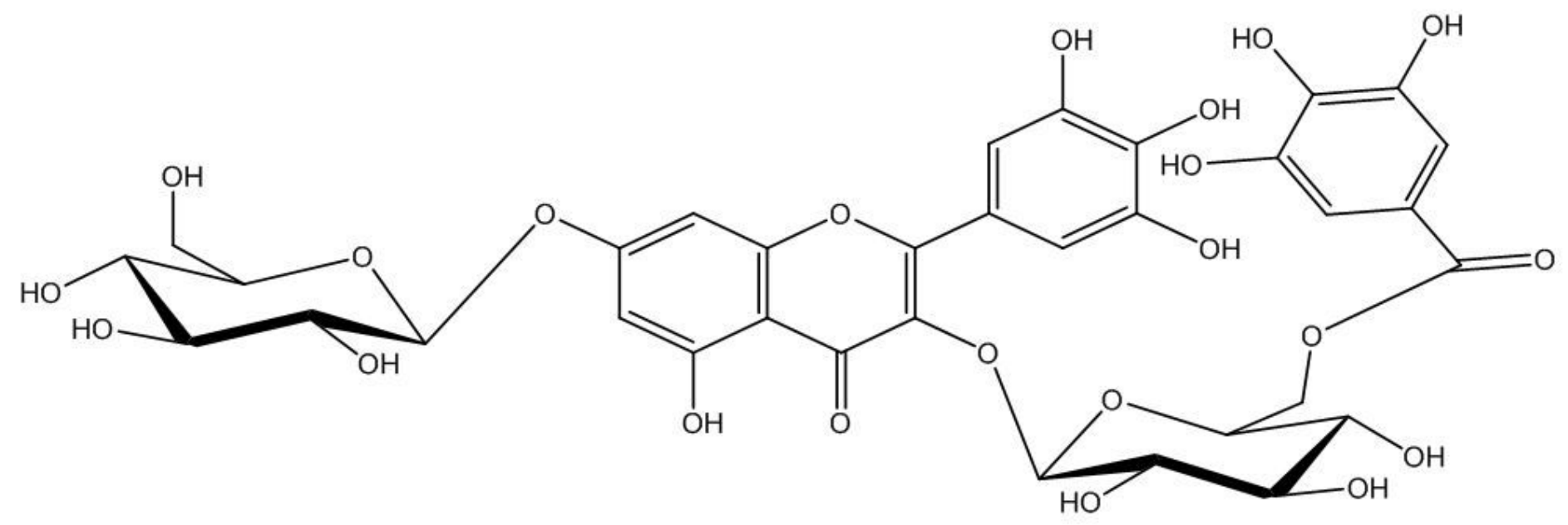

\section{Figure 1}

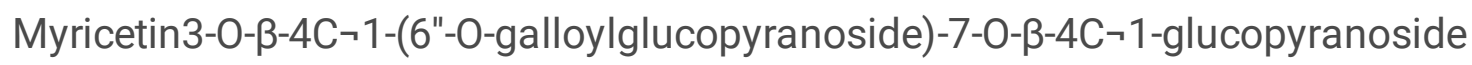




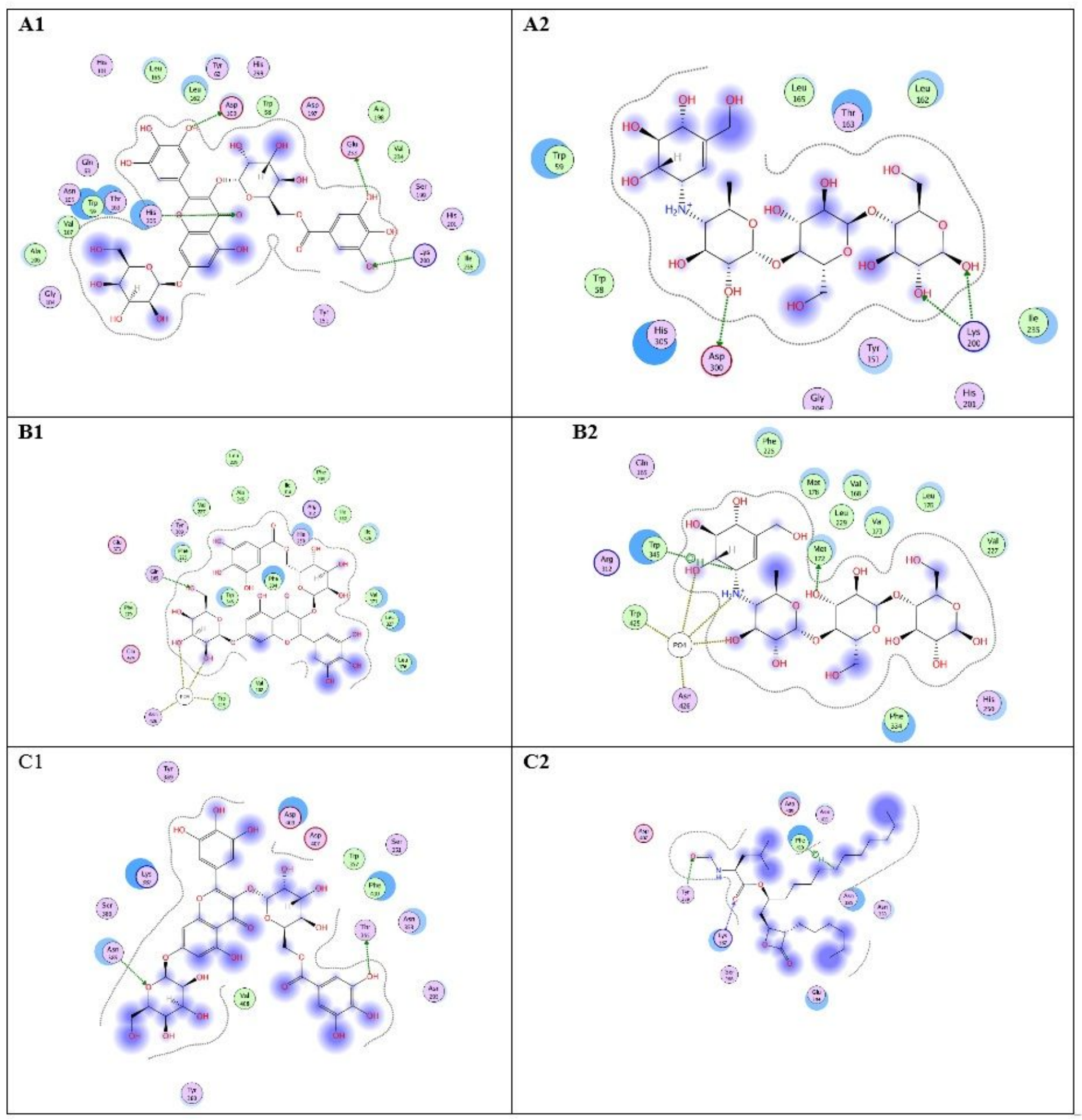

Figure 2

Molecular docking of MGGG with digestive enzymes. (A1) 2D interactions between MGGG and amino acid residues in the active site of a-amylase, (A2) 2D interactions between standard Acarbose and amino acid residues in the active site of a-amylase, (B1) 2D interactions between MGGG and amino acid residues in the active site of $\beta$-glucosidase, (B2) 2D interactions between standard Acarbose and amino acid residues in the active site of $\beta$-glucosidase, (C1) 2D interactions between MGGG and amino acid 
residues in the active site of pancreatic lipase, (C2) 2D interactions between standard rlistate and amino acid residues in the active site of pancreatic lipase. The green dashed lines stand for hydrogen bonds and the purple dashed lines stands for pi interactions.

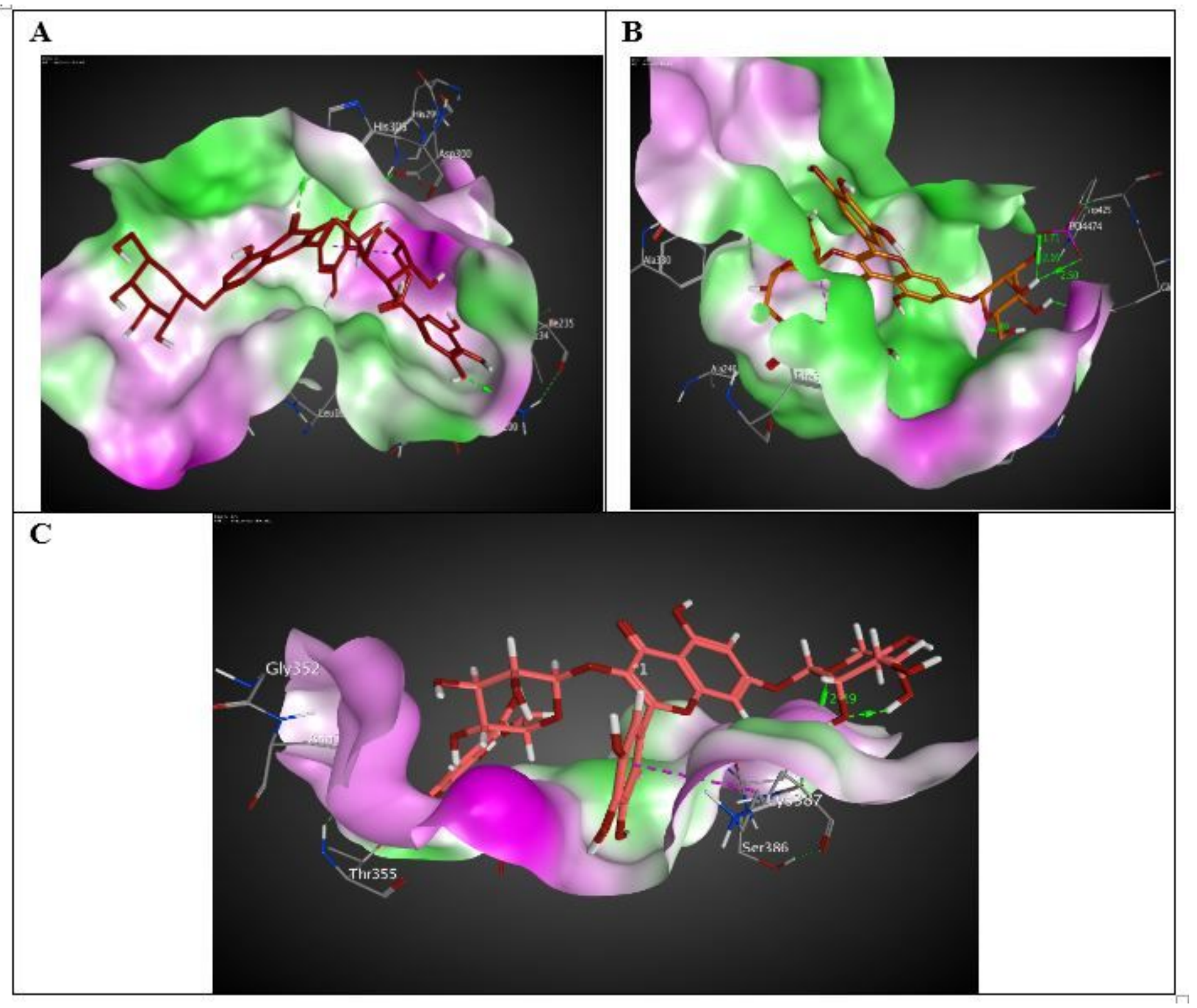

\section{Figure 3}

Mapping surface showing MGGG occupying the active pocket of $\alpha$-amylase (A), $\beta$-glucosidase (B) and pancreatic lipase (C), respectively. 


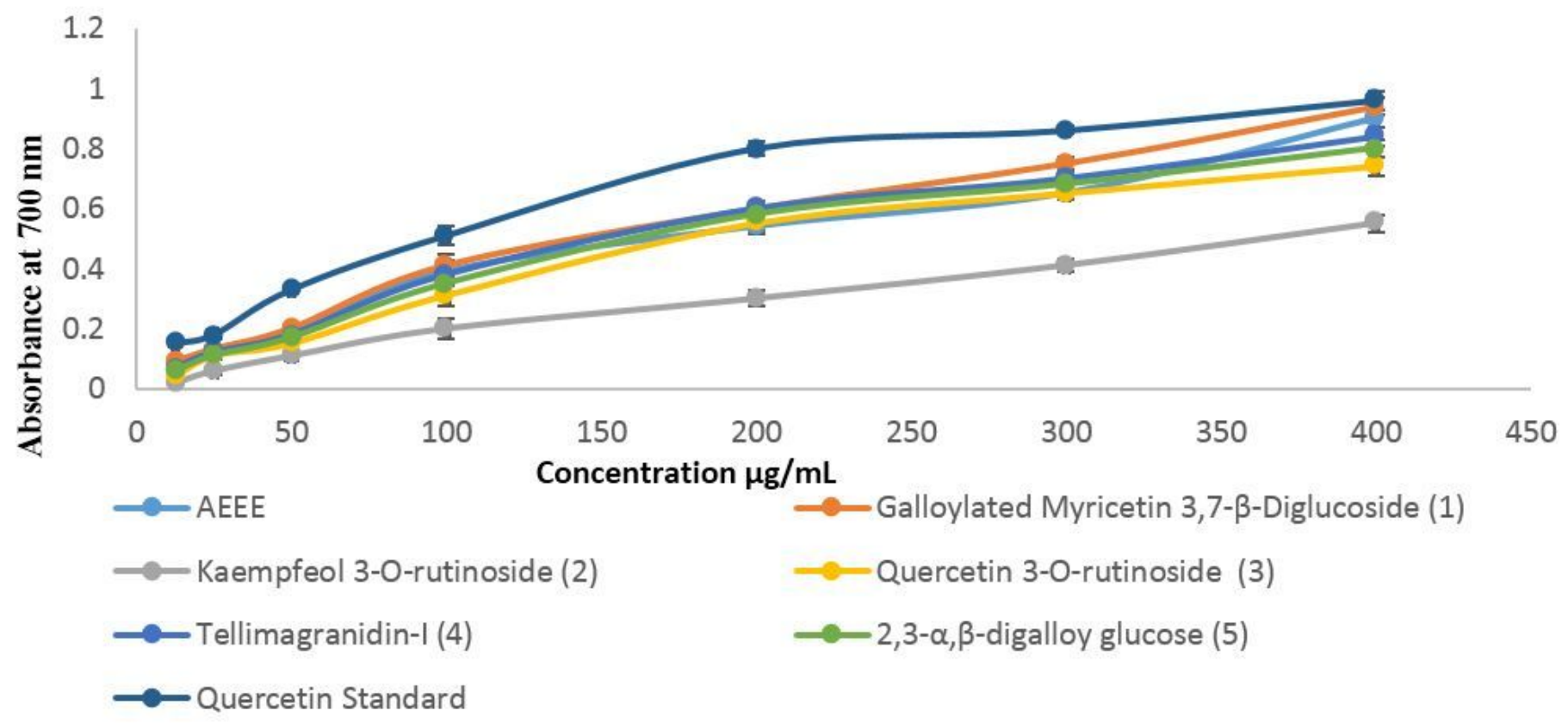

\section{Figure 4}

Reducing power of AEEE and isolated compounds compared with quercetin as standard. Results are given as mean \pm SD of three replicate analyses.

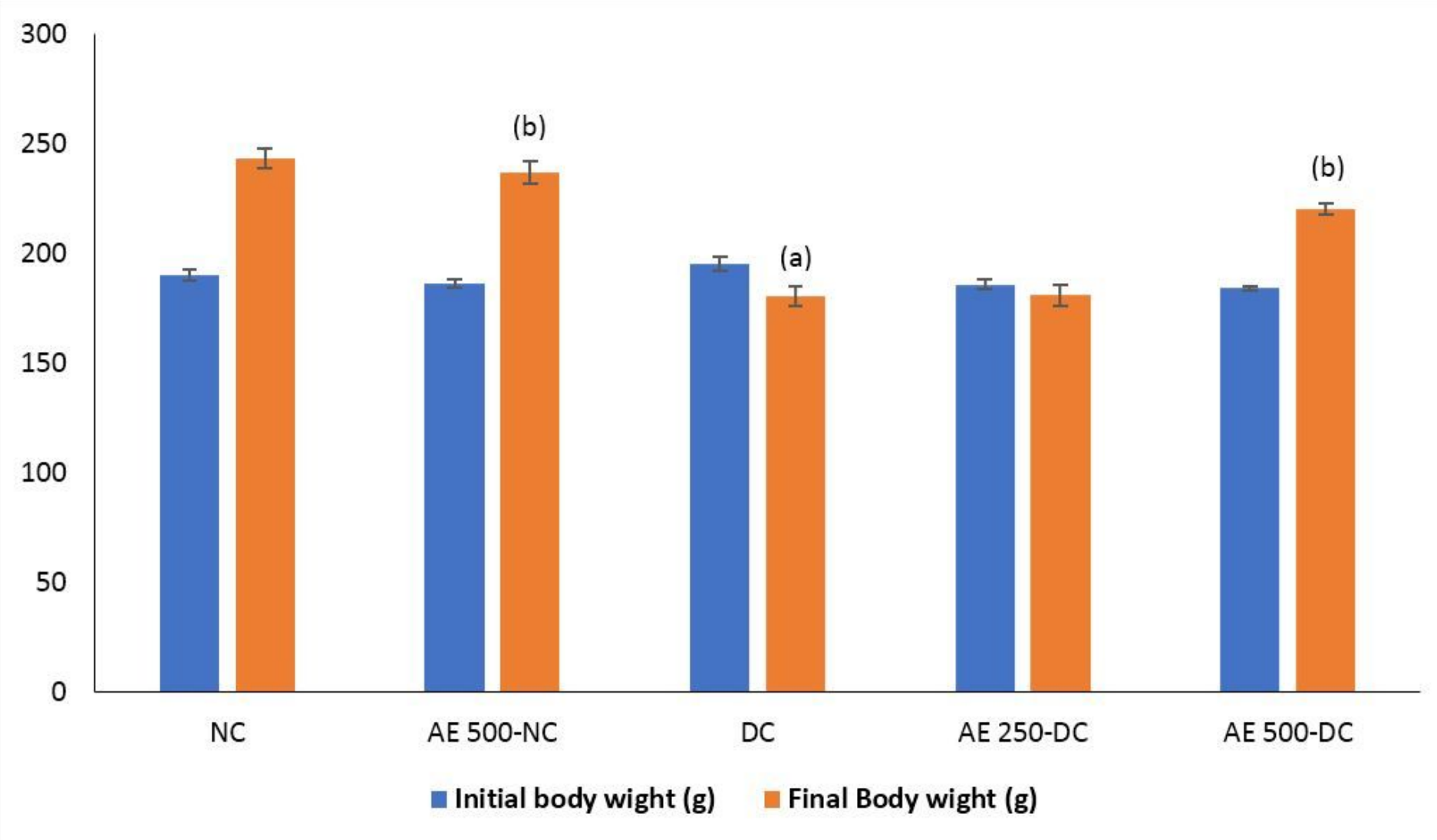

Figure 5 
AEEE effect on body weight during the experimental period (28 days). Results are stated as mean \pm S.D. $(n=6)$. Results are considered significantly different at $P<0.05$. (a) is statistically different from NC group; (b) is statistically different from DC group; (c) is statistically different from standard drug.

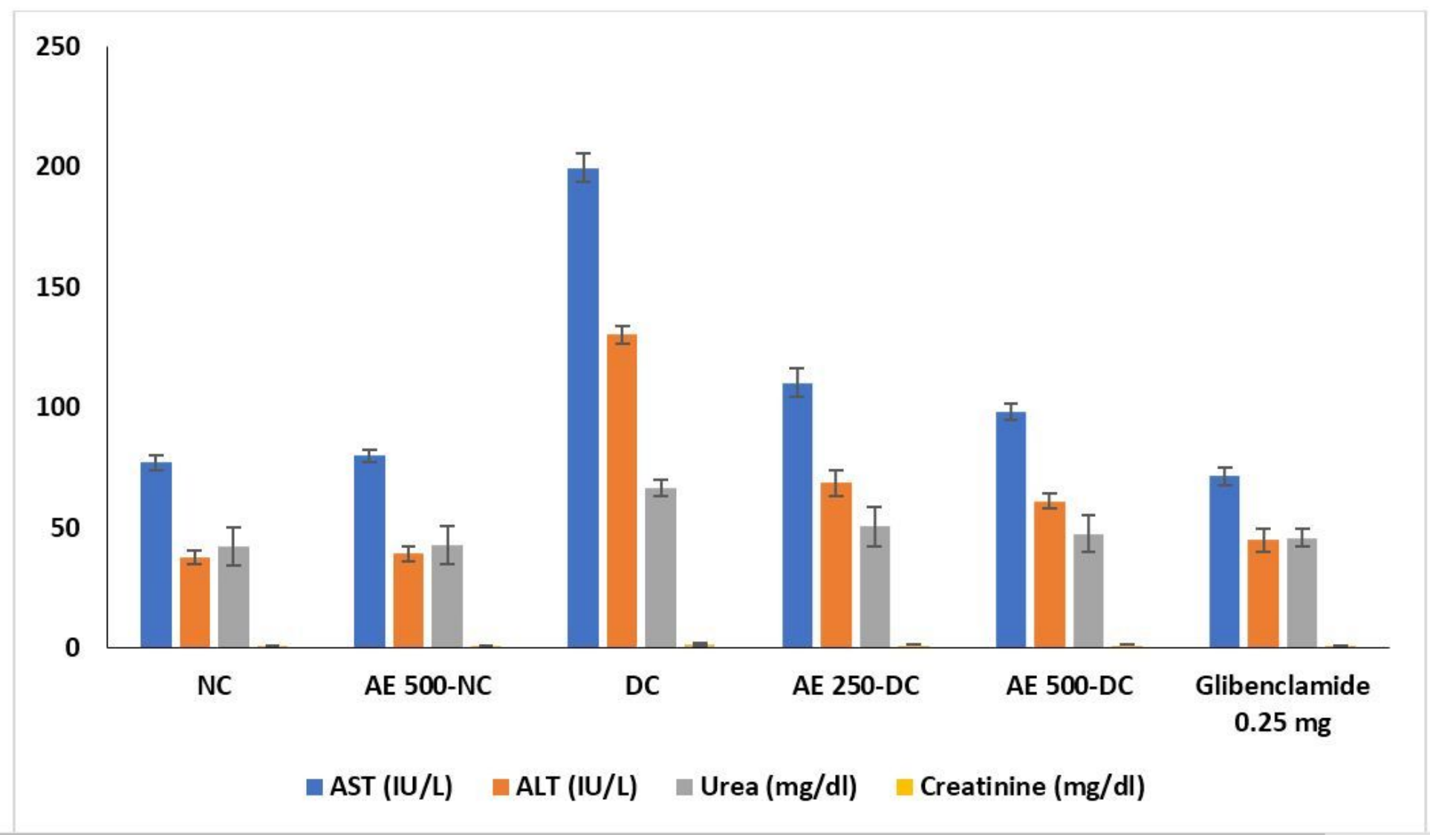

\section{Figure 6}

Effect of AEEE on serum liver and kidney function markers. Results are denoted by means for six rats \pm SD in each group. 


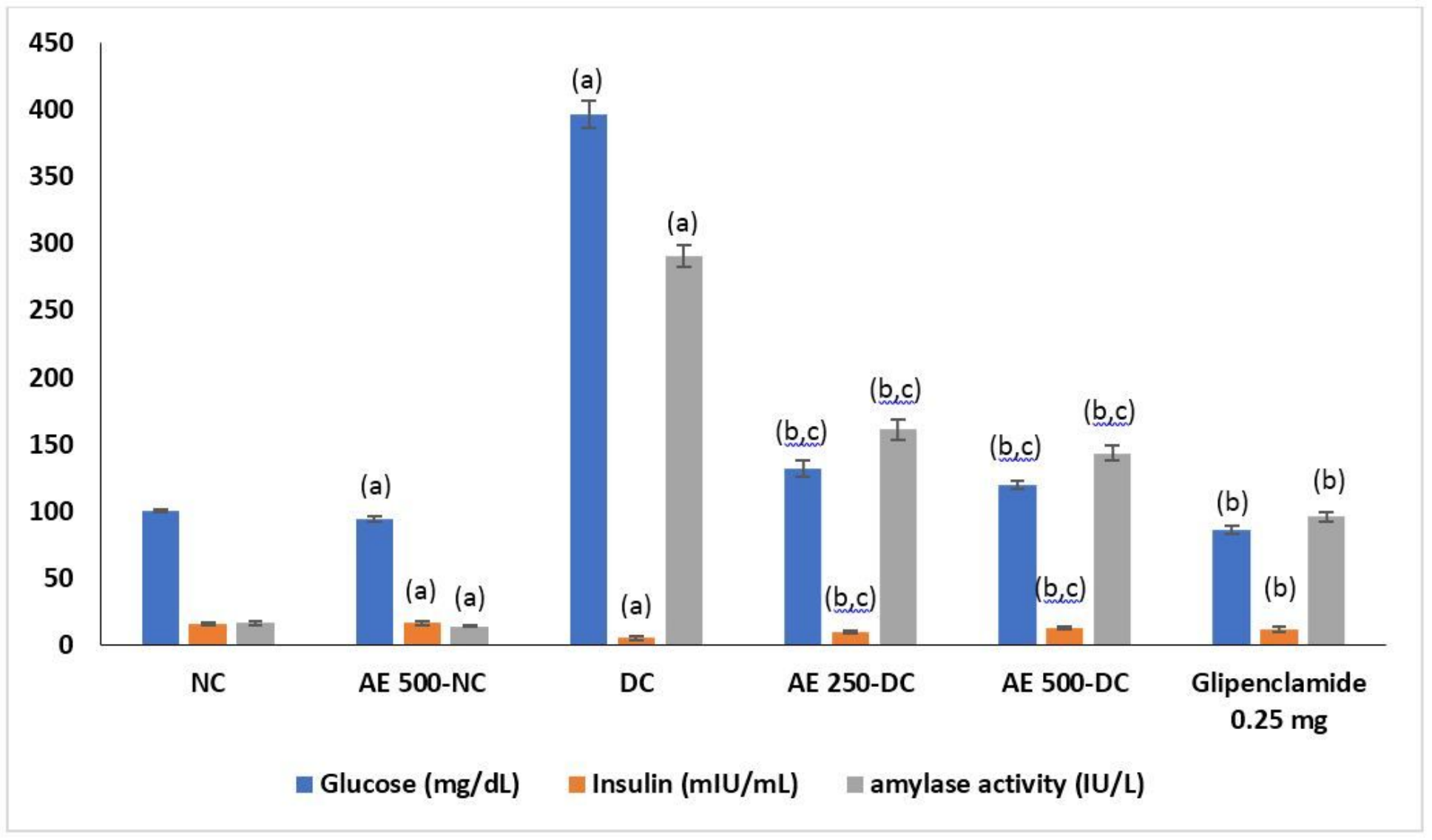

Figure 7

Effect of AEEE on serum blood glucose, insulin and a-amylase. Results are stated as mean \pm S.D, $(n=6)$. Results are considered significantly different at $P<0.05$. (a) is statistically different from NC group; (b) is statistically different from DC group; (c) is statistically different from standard drug. 


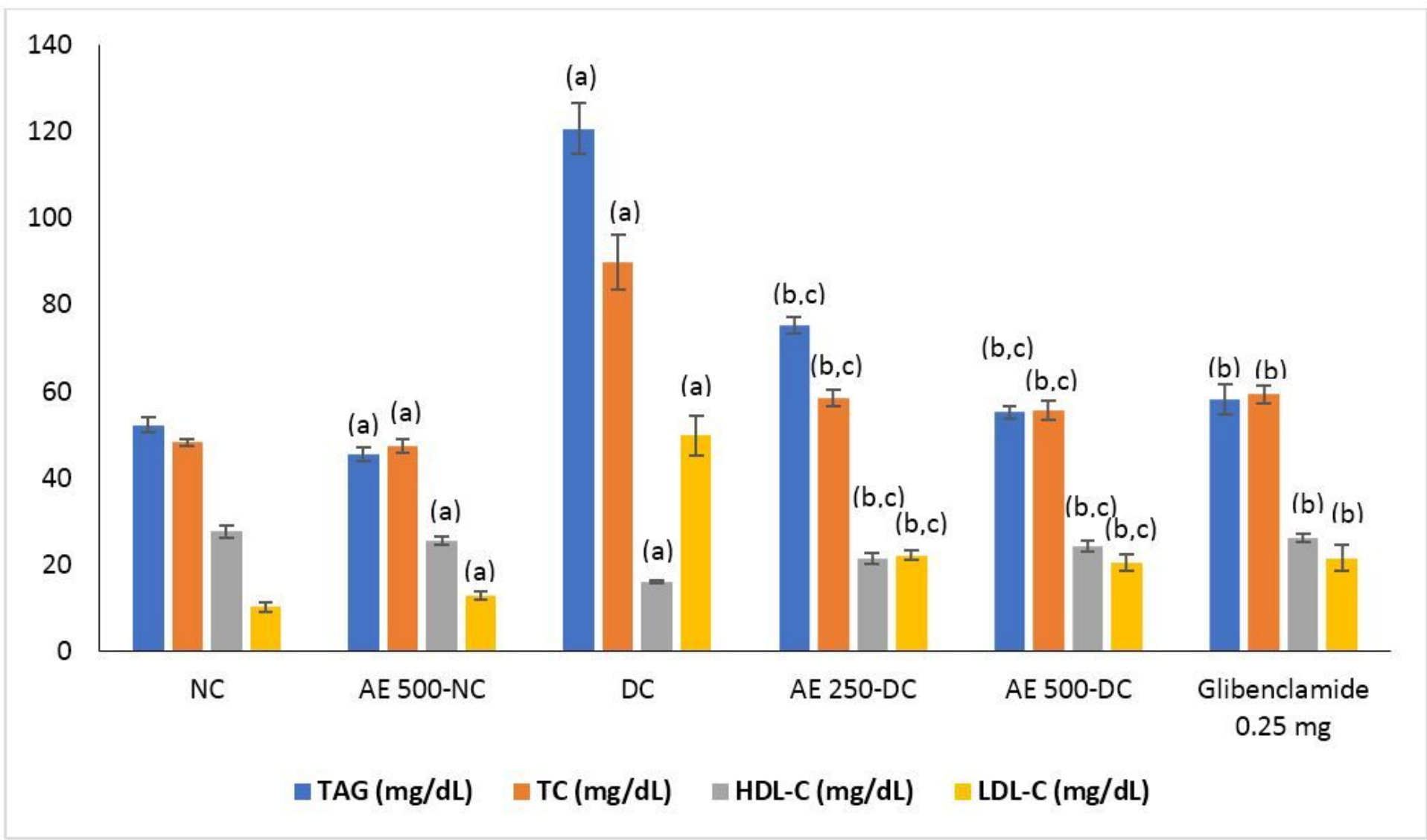

\section{Figure 8}

Effect of AEEE on serum lipid profile. Results are stated as mean \pm S.D. $(n=6)$. Results are considered significantly different at $P<0.05$. (a) is statistically different from NC group; (b) is statistically different from DC group; (c) is statistically different from standard drug. 


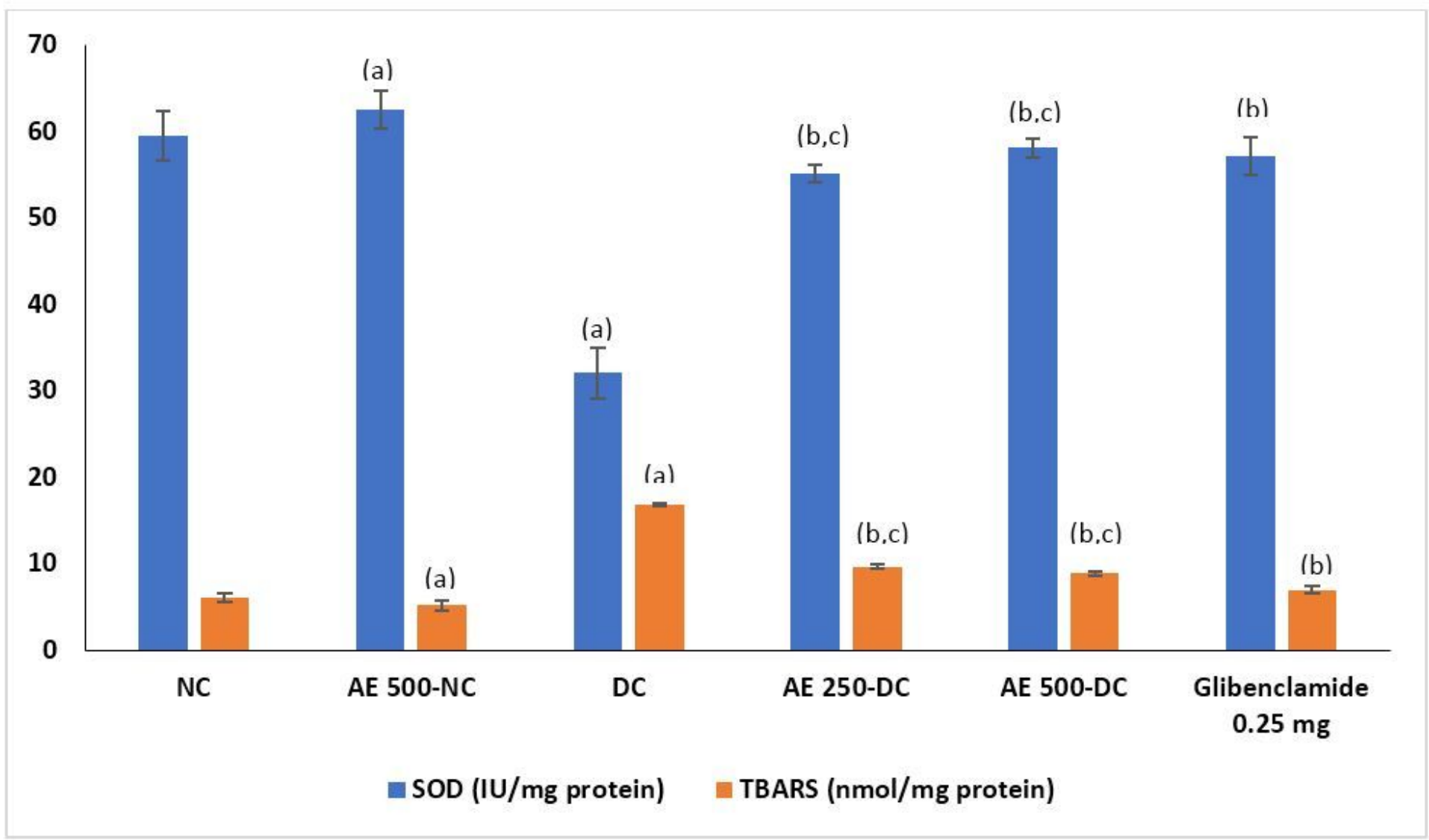

Figure 9

Effect of AEEE on oxidative stress markers of pancreas. Results are stated as mean \pm S.D. $(n=6)$. Results are considered significantly different at $P<0.05$. (a) is statistically different from NC group; (b) is statistically different from DC group; (c) is statistically different from standard drug.
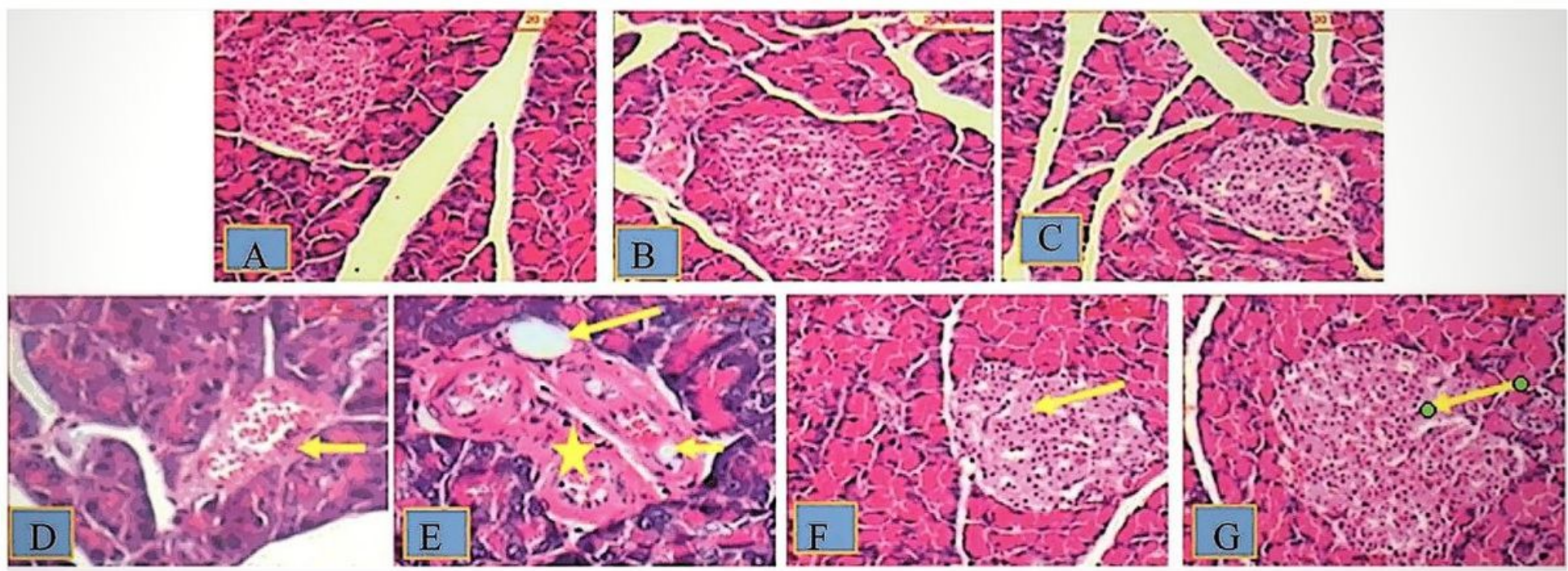

Figure 10

The histological investigation of pancreas. A, B, C: Pancreas sections of NC, AE500-NC and ae250-NC groups respectively, showing denses taining acinar cells and a light-staining islet of Langerhans; D: 
Diabetic rat showing the acinar cells around the islets though seemed to be in normal proportion with up normal morphology with shrunken islet is and intra islet hemorrhage (arrow). E: Diabetic rat showing degenerative islet of Langerhans (asterisk) with different vacuoles size (long arrow) and hemorrhage (short arrow); F: AE 500-DC rat showing the exocrine pancreas appearing more or less as control with fewer degenerative cells in the islet. G: AE250-DC rat showing larger islet than the control one. Exocrine pancreas appeared more or less as control (H \& E, Scale bar: $20 \mathrm{~mm}$ ). 